\title{
FLORA Y VEGETACIÓN ACUÁTICAS DEL LAGO DE ZIRAHUÉN, MICHOACÁN, MÉXICO
}

\author{
Xavier Madrigal Guridi ${ }^{1}$, Alejandro Novelo Retana ${ }^{2}$ y Arturo Chacón Torres ${ }^{1}$ \\ ${ }^{1}$ Instituto de Investigaciones sobre los Recursos Naturales, Universidad \\ Michoacana de San Nicolás de Hidalgo, Av. San Juanito Itzícuaro s/n \\ Morelia, Michoacán \\ ${ }^{2}$ Departamento de Botánica, Instituto de Biología, Universidad Nacional \\ Autónoma de México, Apdo. postal 70-233, 04510 México, D.F.
}

\section{RESUMEN}

El lago de Zirahuén se localiza en la porción centro-norte del estado de Michoacán, dentro de la región hidrológica de la cuenca del Balsas, a 2075 m s.n.m. Es un lago monomíctico, oligotrófico, de tipo endorréico y posee una profundidad máxima de $43 \mathrm{~m}$. Se describe la flora y la vegetación acuáticas del lago, representada por 35 familias, 55 géneros y 93 especies, de las cuales 27 son tolerantes, 42 subacuáticas y 24 acuáticas estrictas. Las formas de vida corresponden a los tipos de enraizadas emergentes, enraizadas sumergidas, enraizadas de hojas flotantes y libremente sumergidas. La vegetación se encuentra distribuida a lo largo de la línea de costa, presentándose a partir de las zonas de inundación temporal y en algunos casos hasta $\operatorname{los} 12 \mathrm{~m}$ de profundidad a manera de individuos aislados. Actualmente la cuenca y el lago muestran signos de deterioro, ocasionados por la explotación irracional de sus recursos, por lo que es urgente tomar las medidas necesarias a corto, mediano y largo plazo, para su conservación.

Palabras clave: distribución de hidrófitas, flora y vegetación acuática, Zirahuén.

\begin{abstract}
Lake Zirahuen is located in the north central area of Michoacan state, within the hydrological region of the Balsas basin, at $2075 \mathrm{~m}$ above sea level. The lake is monomictic, oligotrophic, endorreic and has a maximum depth of $43 \mathrm{~m}$. The flora and the aquatic vegetation are described. Of the 93 species (55 genera, 35 families) that occur, 27 are tolerant, 42 subaquatic and 24 are strictly aquatic. Plant communities are comprised of hydrophytes that are attached emergent, attached submerged, floating leaved and free submerged. The aquatic vegetation is distributed along the lake shore, extending from the regions of temporary flooding to areas of open water $12 \mathrm{~m}$ deep. At present both, the
\end{abstract}


catchment basin and the lake itself are showing signs of ecological degradation due to the intensive exploitation of its resources. Both short and long-term strategies need to be developed to stem further degradation of the lake.

Key words: flora and aquatic vegetation, hydrophytes distribution, Zirahuen.

\section{INTRODUCCIÓN}

El estado de Michoacán posee varios cuerpos de agua, entre los que destacan por su extensión, importancia cultural y biológica los lagos de Cuitzeo, Pátzcuaro y Zirahuén. En estos ecosistemas la vegetación acuática cumple diversas funciones ecológicas, es fuente de alimento para numerosos herbívoros, y sirve de refugio y anidamiento para las aves, peces y anfibios, además reduce la velocidad de las corrientes y la influencia del oleaje, disminuyendo los efectos de la erosión en la línea de costa; desempeña asimismo un importante papel en la composición química y la calidad del agua, ya que regula la concentración de bióxido de carbono, oxígeno y de algunos nutrientes tales como el fósforo y el nitrógeno (Brown, 1976).

En lagos oligotróficos, con escasa cantidad de nutrientes y aguas transparentes, la vegetación enraizada sumergida puede encontrarse a profundidades mayores de $10 \mathrm{~m}$, estando los límites de colonización de las plantas acuáticas sumergidas relacionados con la irradiación disponible (Chambers y Kalff, 1985).

Ikushima (1987) estableció la relación entre la productividad de la vegetación acuática y la disponibilidad de luz, considerando para ello las diferentes formas de vida.

Kaul y Kaul (1987) analizaron la función que las hidrófitas desempeñan en los ecosistemas acuáticos tropicales de aguas interiores, con el propósito de optimizar el manejo y aprovechamiento de los recursos de estas zonas.

El uso y la comparación de diferentes tipos de transectos lineales, como base práctica para el estudio de la distribución y caracterización de la vegetación acuática, han sido propuestos por Titus (1993), quien además hace recomendaciones para su empleo con el fin de ocasionar el menor impacto posible a las comunidades vegetales.

En México se han llevado a cabo estudios relacionados con las comunidades de hidrófitas en diversos cuerpos de agua. Lot y Novelo (1988) describieron la vegetación del lago de Pátzcuaro, haciendo referencia a las formas de vida, distribución y diversidad en las diferentes zonas del lago.

Rojas y Novelo (1995) analizaron el universo vegetal del lago de Cuitzeo, Michoacán, donde registraron una alta riqueza florística, con 25 especies acuáticas estrictas, 30 subacuáticas y 37 tolerantes. Ilustraron las asociaciones más importantes de plantas vasculares y su distribución vertical en secciones diagramáticas. 
Lot et al. (1999) recopilaron y sintetizaron los datos existentes con relación a la flora, taxonomía y nuevos registros de las angiospermas acuáticas estrictas de México. El catálogo enumera 118 especies agrupadas en 45 géneros y 24 familias. Ilustran cada una de las especies, presentando la información referente a manera de ficha, incluyendo la sinonimia científica más común y los nombre vulgares; se define además la distribución de cada una de las hidrófitas en México y en el mundo, y se proporcionan datos generales de los hábitats en que se encuentran. Finalmente se analiza su situación actual y el riesgo de extinción.

Son escasos los estudios realizados en el lago de Zirahuén. Pérez-Calix (1996) describió de manera breve la vegetación acuática y mencionó que su distribución se encuentra limitada a las orillas y áreas someras, formando una franja angosta a lo largo de la línea de costa. Señaló la presencia de 4 hidrófitas enraizadas sumergidas, 7 hidrófitas enraizadas emergentes y 21 especies ligadas a los suelos temporal o permanentemente inundados.

Chacón y Múzquiz (1991) realizaron el reconocimiento ambiental de la cuenca y el lago de Zirahuén, concluyendo con respecto a las hidrófitas, que constituyen la comunidad menos estudiada. Los mismos autores indicaron que este cuerpo de agua posee un patrón de distribución con una zonación bien definida.

Antaramián y Ortega (1996) evaluaron el riesgo de erosión del suelo para la cuenca de Zirahuén, considerando que éste se halla en un intervalo de ligero a moderado, para lo cual tomaron en cuenta los factores climáticos, edáficos y topográficos.

Por lo anterior, se considera de especial interés enriquecer el conocimiento relacionado con la vegetación acuática de este ecosistema, ya que probablemente en un futuro, y debido a las alteraciones causadas por las actividades humanas, no será posible obtener la información necesaria para un apropiado manejo y conservación de éste y de otros recursos del lago y de su cuenca.

\section{ÁREA DE ESTUDIO}

Ubicación geográfica

La cuenca de Zirahuén se localiza en la Subprovincia Neovolcánica Tarasca, dentro de la región hidrológica del Balsas, entre las coordenadas $19^{\circ} 21^{\prime} 14^{\prime \prime}$ y $19^{\circ} 29^{\prime} 32^{\prime \prime}$ de latitud norte y $101^{\circ} 30^{\prime} 33^{\prime \prime}$ y 101²46'15" de longitud oeste (Chacón y Múzquiz, 1991) (Fig. 1). El cuerpo lacustre se ubica en la región oeste de la cuenca a 2075 m s.n.m. y posee una superficie de $10.48 \mathrm{~km}^{2}$. Es un lago monomíctico, con estratificación en verano y mezcla en invierno (Chacón y Rosas-Monge, 1998). 


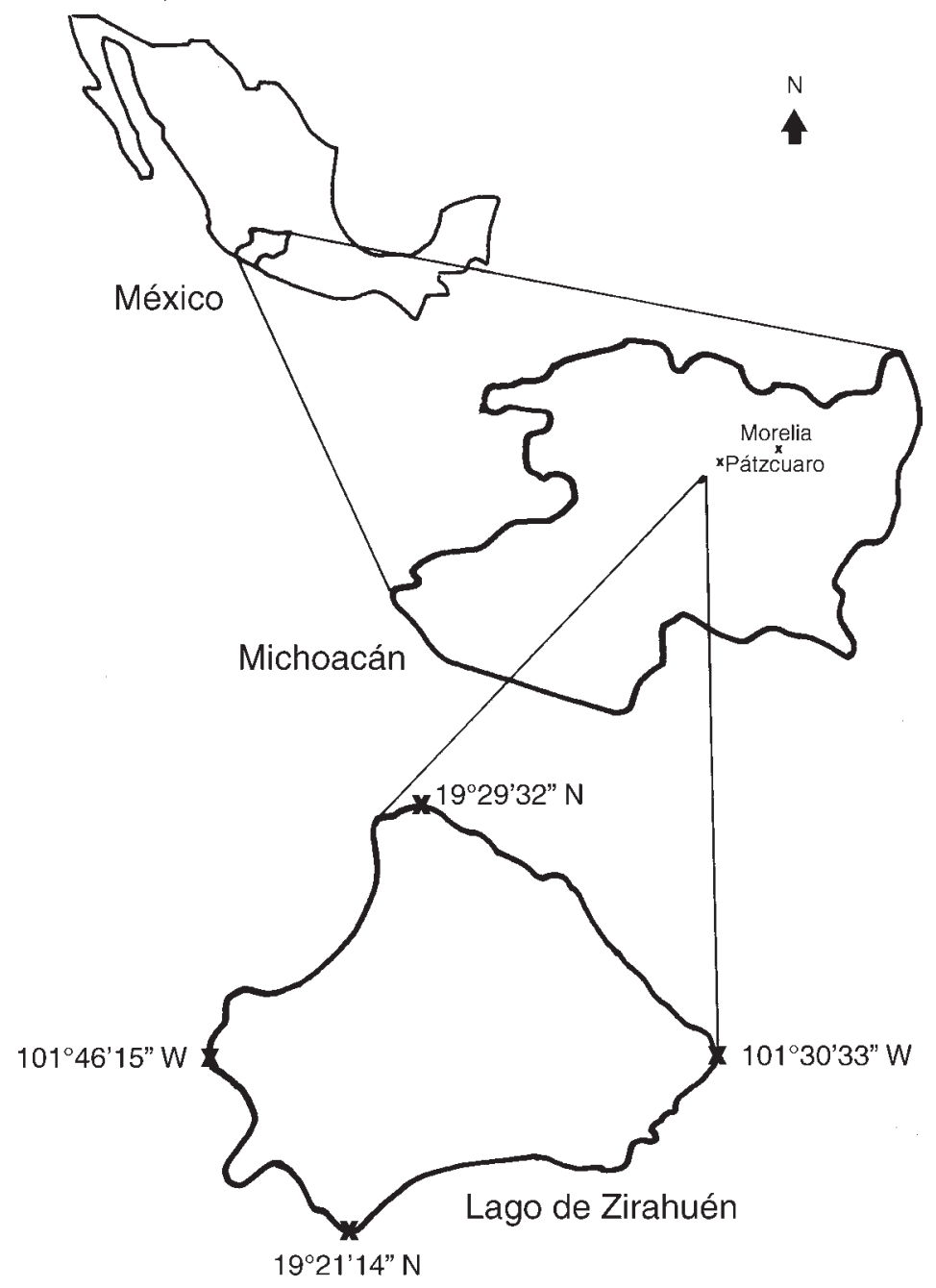

Fig. 1. Ubicación geográfica del lago de Zirahuén, Michoacán, México.

Calidad del agua

Los valores de calidad del agua y productividad primaria obtenidos por Chacón y Rosas-Monge (op cit.) caracterizan a Zirahuén como un lago oligotrófico. Los valores promedio para los parámetros medidos son: temperatura del agua: $16.5{ }^{\circ} \mathrm{C}$, transparencia en disco de Secchi: $6.0 \mathrm{~m}$, profundidad de la zona eufótica: $15.0 \mathrm{~m}$, conductividad eléctrica: $75.0 \mu \mathrm{Sem}^{-1}, \mathrm{pH}: 8.1$ y una productividad primaria por fitoplankton de $15.75 \mathrm{~g} / \mathrm{cm}^{-2}$. 
Fisiografía

La cuenca del lago de Zirahuén se ubica en la vertiente sur de la provincia fisiográfica del Cinturón Volcánico Transmexicano, en la Subprovincia Neovolcánica Tarasca. La zona se caracteriza por la presencia de rocas volcánicas de diversos tipos, depositadas en periodos sucesivos desde mediados del Terciario hasta el presente (Israde, 1999).

\section{Geología}

Las rocas de la cuenca corresponden al Terciario y Cuaternario, como consecuencia de la alta actividad volcánica que se presentó en la zona. En su mayoría las rocas se encuentran representadas por basaltos y andesitas. El lago se formó durante el Pleistoceno, debido a una obstrucción por un derrame de lava (ChacónTorres y Rosas-Monge, 1998).

\section{Suelos}

Los suelos de la cuenca se originaron recientemente, a partir de rocas y cenizas volcánicas. En su mayor extensión corresponden a los andosoles ócrico y húmico y en menores proporciones se presentan el acrisol órtico, cambisol dístico, feozem y luvisol crómico (Chacón y Múzquiz, 1991).

\section{Clima}

El clima de la cuenca es de tipo $\mathrm{Cw}\left(\mathrm{w}_{2}\right)(\mathrm{w}) \mathrm{i}$, templado con lluvias en verano, con proporción de precipitación invernal inferior a 5\%; la temperatura media anual es de $15.7^{\circ} \mathrm{C}$ y el promedio de precipitación anual de $1182.6 \mathrm{~mm}$. (Anónimo, 1985).

Hidrología

El afluente principal es el río La Palma o El Silencio, clasificado como de cuarto orden y de tipo perenne. Existen otras corrientes intermitentes de segundo y tercer orden en zonas de pendientes poco pronunciadas (Rosas, 1997).

Vegetación

En la cuenca del lago Zirahuén se presentan cinco tipos principales de vegetación: bosque de coníferas, bosque de encino, bosque mesófilo de montaña, pastizal y vegetación acuática. De éstos, los más extensos son los bosques de coníferas y los de encino. Por el contrario, el bosque mesófilo de montaña es de superficie reducida (Pérez-Calix, 1996).

\section{Ictiofauna}

De acuerdo con Chacón y Rosas-Monge (1998) la ictiofauna está constituida por cinco especies nativas (Chirostoma estor copandaro, Chirostoma atenuatum 
zirahuen, Allophorus robustus, Goodea atripinnis y Neoophorus diazi) y tres introducidas (Micropterus salmoides, Oncorhynchus mykiss y Cyprinus carpio). De éstas, $M$. salmoides, C. estor copandaro y C. atenuatum zirahuen, constituyen más de $90 \%$ del volumen capturado, el cual se estimó entre 1984 y 1993 en 12.53 toneladas métricas.

\section{MATERIALES Y MÉTODOS}

Los muestreos y colectas se realizaron en dos periodos diferentes del año, considerando uno para la temporada seca y otro para la de lluvias; de esta manera se registraron los cambios estacionales en las comunidades vegetales. Cada uno de los sitios fue ubicado cartográficamente, tomando las lecturas en unidades cartográficas del sistema de proyección Universal Transversa de Mercator (UTM).

Para determinar la distribución vertical y horizontal de la vegetación se realizaron perfiles a partir de la línea de costa del lago en forma perpendicular a la orilla, explorando hasta los quince metros de profundidad. Se empleó un carrete con cordel graduado a cada metro, con longitud total de 120 metros y un profundímetro digital, así como una brújula sumergible para poder definir el rumbo y la posición del transecto empleando equipo de buceo autónomo tipo SCUBA, basado en el método propuesto por Titus (1993). La pendiente se determinó en el campo utilizando el cordel graduado y un profundímetro digital incorporado a una computadora de buceo UWATEC, ubicando las distancias sobre la superficie del fondo desde la orilla del lago a intervalos de $0.5 \mathrm{~m}$ de profundidad, para posteriormente calcular el promedio de la pendiente en tanto por ciento, con relación a las distancias y profundidades.

Los perfiles fueron realizados en ocho diferentes sitios de la zona litoral (Fig. 2), seleccionados como áreas de muestreo con base en las diferentes condiciones ambientales en cada una de ellas, tomando en cuenta algunos de los factores que, de acuerdo con lo que sugiere la bibliografía consultada, pueden influir en la distribución y presencia de los organismos. De este modo se consideró la pendiente, tipo de sustrato, transparencia, influencia de vientos y oleaje y las diferentes actividades humanas realizadas en los márgenes del lago.

La información relacionada con el tipo de sustrato en cada una de las estaciones de muestreo fue obtenida a partir de los resultados de Corona (com. pers.).

La transparencia del agua se midió directamente en cada una de las estaciones de muestreo a $50 \mathrm{~m}$ de la orilla, utilizando un disco de Secchi (SD) de $20 \mathrm{~cm}$ de diámetro, en las diferentes épocas del año. 


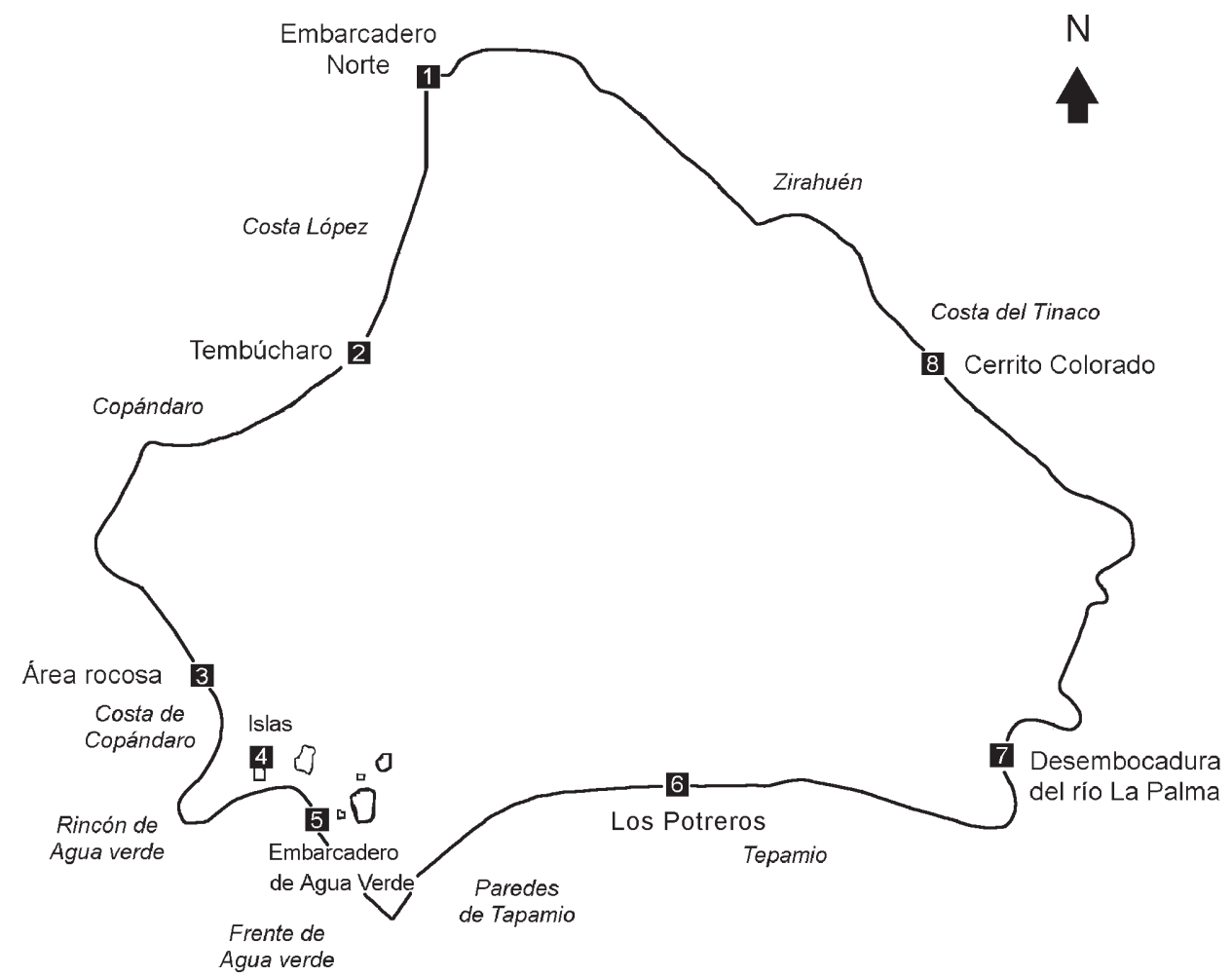

Fig. 2. Ubicación de los sitios de muestreo en el lago de Zirahuén, Michoacán, México.

Para determinar la influencia de los vientos y el oleaje en las estaciones muestreadas, se revisaron los resultados obtenidos por Campos et al. (1997). Posteriormente se calculó la longitud efectiva de viento (Lf) utilizando la técnica propuesta por Hakanson (1981).

Las actividades humanas en diversas zonas del lago y en sus orillas se registraron directamente o a través de la información proporcionada por los pobladores que laboran en la localidad.

La obtención del material botánico se realizó mediante exploraciones e inmersiones periódicas, empleando equipo de buceo SCUBA, de agosto de 1998 a agosto del 2000. Los ejemplares se depositaron en el Herbario Nacional (MEXU) ubicado en el Instituto de Biología de la Universidad Nacional Autónoma de México.

En la elaboración del listado florístico se utilizó el sistema de clasificación propuesto por Cronquist (1981). Algunas familias designadas con nombres distintos empleados por otros autores se indican entre paréntesis. 
Los análisis estadísticos y gráficas se realizaron con el programa Microsoft Excel $2000^{\circledR}$.

Para determinar los tipos de plantas acuáticas así como las formas de vida se consideraron los siguientes criterios propuestos por Ramos y Novelo (1993) y Lot et al. (1999).

Tipos de plantas acuáticas

Acuáticas estrictas (a). Las plantas que permanecen prácticamente todo su ciclo de vida dentro del agua, ya sea sumergidas, emergiendo o flotando.

Subacuáticas (s). Son las plantas que llevan a cabo gran parte de su ciclo de vida en el agua y no pueden sobrevivir por un largo periodo de tiempo en suelos completamente secos; se les encuentra generalmente a las orillas de los ecosistemas acuáticos.

Tolerantes (t). Son aquellas que llevan a cabo gran parte de su ciclo de vida en suelos completamente secos, pero que pueden tolerar por corto tiempo el suelo inundado o un alto contenido de humedad en éste.

Formas de vida

Hidrófita enraizada emergente: arraigada al sustrato y gran parte de ella se levanta por encima del agua, manteniendo sus estructuras reproductoras en el aire.

Hidrófita enraizada sumergida: arraigada al sustrato con todas sus partes vegetativas inmersas en el agua; los órganos reproductores pueden presentarse sumergidos, flotar o quedar por encima de la superficie del agua.

Hidrófita de hojas flotantes: arraigada al sustrato, manteniendo postradas sus hojas sobre la superficie del agua al igual que las flores, aunque éstas se levantan ligeramente.

Hidrófita libre flotadora: Sus estructuras vegetativas y reproductoras se mantienen emergidas y únicamente su sistema radical se encuentra sumergido. Son dispersadas libremente por la acción de los vientos y corrientes.

Hidrófita libre sumergida: no enraizadas al fondo, generalmente con todas las estructuras vegetativas sumergidas y sólo las reproductoras emergen ligeramente de la superficie del agua.

\section{RESULTADOS}

\section{Vegetación}

Las hidrófitas del lago de Zirahuén presentan una zonificación definida principalmente por la profundidad. Las más abundantes y que ocupan mayor 
superficie son las hidrófitas acuáticas y subacuáticas. Colindan con ellas zonas de inundación temporal que corresponden al bosque mesófilo de montaña.

La vegetación acuática y subacuática se presentan de manera heterogénea a lo largo de la zona litoral, siendo las comunidades próximas a la desembocadura del río La Palma las que muestran cambios más drásticos con relación a su estructura y composición, consecuencia de la escasa pendiente y las marcadas variaciones en el límite de la línea de costa y el nivel del lago en las diferentes estaciones del año.

Los individuos que conforman el grupo de las plantas tolerantes se encontraron generalmente presentes en las orillas del lago o en sus proximidades y solamente en algunos casos o durante la temporada en que el lago alcanzó su nivel máximo, se les observó cubiertas por el agua. En su mayoría presentan formas biológicas herbáceas y arbustivas.

Algunas de las especies arbóreas del bosque mesófilo de montaña que se desarrollan a las orillas del lago, tales como Alnus acuminata y Salix bonplandiana, pueden quedar parcialmente sumergidas durante la temporada de lluvias, tolerando hasta un metro de profundidad durante dos o tres meses.

En el caso de las comunidades de plantas herbáceas, éstas se encuentran determinadas de acuerdo con su forma de vida predominante. En el lago de Zirahuén, la superficie cubierta por las hidrófitas enraizadas sumergidas, representadas por 12 especies, es la más extensa, seguida por la dominada por las hidrófitas enraizadas emergentes con un total de 78 especies. Existen comunidades de pequeña extensión y distribución restringida al sureste del lago, en las que prevalecen dos especies de hidrófitas de hojas flotantes. Solamente se registró la presencia de una especie de hidrófita libremente sumergida (Utricularia aff. macrorhiza). Las hidrófitas libremente flotadoras están ausentes.

En cuanto al tipo de planta acuática, se ubicaron 24 especies en la categoría de acuáticas estrictas, 42 subacuáticas y 27 tolerantes.

Formas de vida

Hidrófitas enraizadas emergentes. Son plantas arraigadas al sustrato, cuyos tallos, hojas y órganos reproductores son aéreos y por lo tanto, se encuentran por encima de la superficie. En Zirahuén estas comunidades presentan una distribución restringida principalmente a la zona sur y oriente del lago, en comunidades de mediana extensión, aunque con numerosos individuos. Se les encuentra también con frecuencia a manera de angostas franjas y manchones a lo largo de toda la zona litoral. Los elementos principales de estas comunidades son: Typha latifolia, T. domingensis y Schoenoplectus californicus, con alturas promedio de $2.5 \mathrm{~m}$, en zonas de hasta $2 \mathrm{~m}$ de profundidad como máximo. Las zonas más extensas del tular durante la estación seca pueden quedar temporalmente fuera del agua y con frecuencia se encuentran en convivencia con vegetación subacuática. 
Asociadas al tular, en lugares abiertos, crecen especies de menor talla y con diferente forma de vida, principalmente hidrófitas enraizadas sumergidas como Potamogeton illinoensis, Ludwigia palustris y Najas guadalupensis. Particularmente en la zona sureste se desarrollan las hidrófitas de hojas flotantes Nymphaea odorata y Nymphoides fallax (Fig. 3a).

Hidrófitas enraizadas sumergidas. Dentro de esta forma de vida quedan incluidas todas las especies cuyas estructuras foliares y reproductoras permanecen completamente sumergidas, aunque en algunos casos pueden tener sus órganos reproductores aéreos emergiendo por encima de la superficie o ser flotantes. Las especies mejor representadas con esta forma de vida en el lago son: Potamogeton illinoensis, Najas guadalupensis y las algas Chara excelsa y Nitella opaca.

La escasa extensión de la zona litoral, determinada por la pendiente pronunciada en la mayor parte de las orillas del lago, ocasionan que las comunidades de hidrófitas con esta forma de vida, se presenten a manera de una franja angosta a lo largo de la orilla. Las especies citadas se encuentran desde $0.5 \mathrm{~m}$ de profundidad hasta zonas de 8 ó $9 \mathrm{~m}$; aunque en algunos casos se hallaron individuos aislados de Nitella opaca hasta los $12 \mathrm{~m}$ de profundidad durante la estación seca, cuando la transparencia del agua es mayor. Estas comunidades están bien representadas a lo largo de la zona litoral de todo el lago, con excepción de la zona sureste, en la que el sustrato es predominantemente rocoso y la vegetación sólo puede desarrollarse en sitios muy reducidos.

Es común encontrar áreas donde el predominio de una especie es muy marcado con respecto a las otras, existiendo comunidades dominadas casi en su totalidad por Potamogeton illinoensis, Chara excelsa o Nitella opaca.

Hidrófitas enraizadas de hojas flotantes. Son plantas enraizadas al sustrato, cuyas hojas flotan sobre la superficie del agua y sus órganos reproductivos emergen por encima de la misma. Las hidrófitas que poseen esta forma de vida sólo se hallan bien representadas en las áreas protegidas de la zona sur y sureste del lago, en áreas de escasa pendiente, en medio de los tulares o en sus márgenes, a profundidades inferiores a $1.5 \mathrm{~m}$ y en manchones de extensión reducida. Las especies registradas fueron Nymphaea odorata y Nymphoides fallax. Asociadas a ellas se encuentran algunas hidrófitas enraizadas emergentes de las especies Schoenoplectus californicus y Typha spp, así como algunas hidrófitas enraizadas sumergidas tales como Ludwigia palustris y Potamogeton illinoensis (Fig. 3b).

Hidrófitas libremente sumergidas. Se encontró una sola especie con esta forma de vida, Utricularia aff. macrorhiza. Se localiza exclusivamente en zonas protegidas del sur del lago y poco profundas ( 2 a $3 \mathrm{~m}$ ). Es poco abundante, aunque 

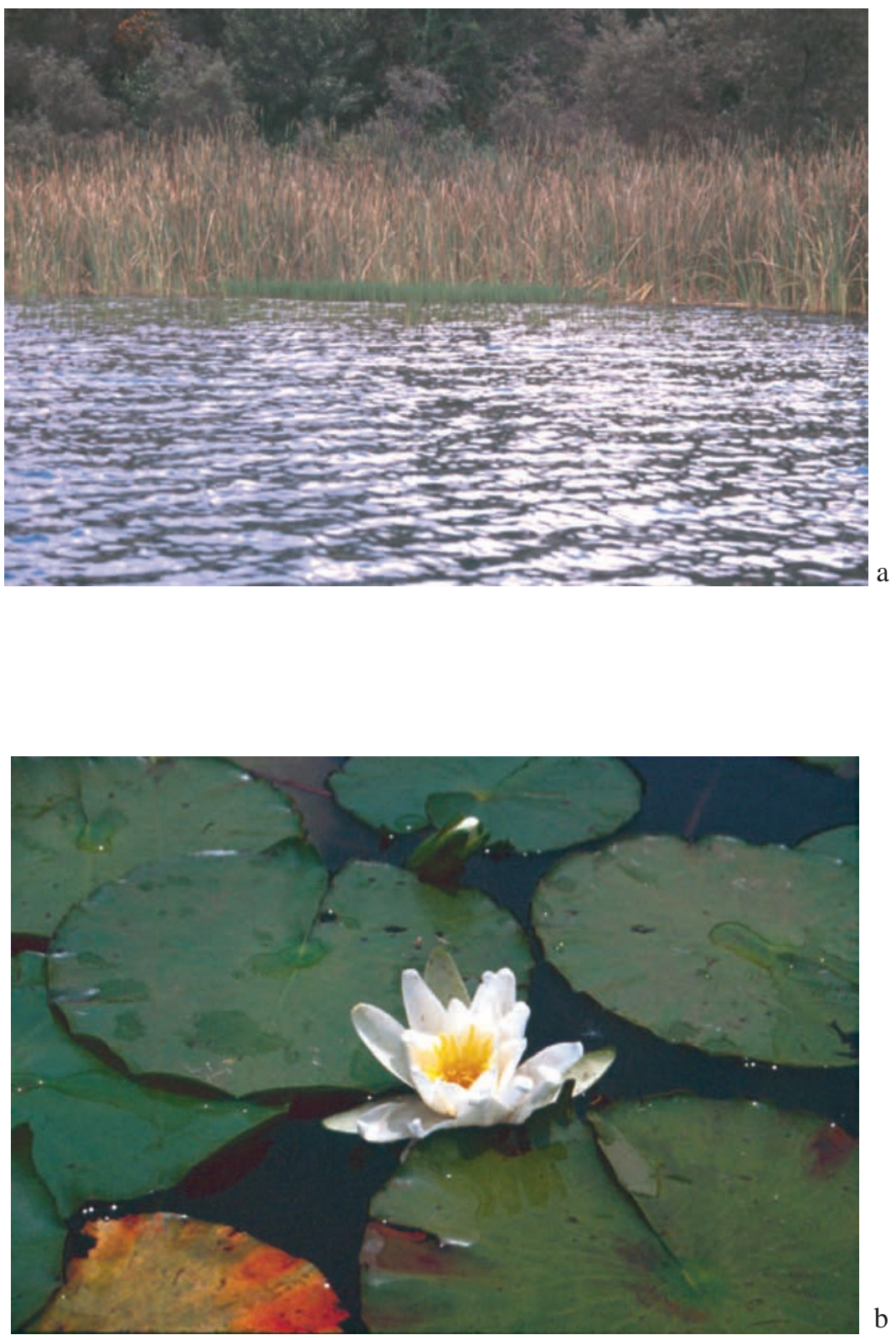

Fig. 3. Formas de Vida. a) Comunidad de hidrófitas enraizadas emergentes dominadas por Typha spp. en las áreas someras de la zona litoral del lago de Zirahuén, Michoacán, México. b) Nymphaea odorata; hidrófita de hojas flotantes. 
algunos individuos pueden alcanzar tallas mayores a $1.5 \mathrm{~m}$. Las plantas crecen postradas libremente sobre el sustrato o sobre otras plantas acuáticas. En ningún caso y en ninguna de las diferentes épocas del año fue posible encontrar individuos con flores o frutos, por lo que no se determinó con precisión a nivel de especie.

Características generales de las estaciones de muestreo

A este respecto cabe apuntar que la distribución anual de la dirección del viento en el lago de Zirahuén es de: oeste $2 \%$, suroeste $67 \%$, sur $31 \%$, con promedio máximo de velocidad de $5 \mathrm{~m} / \mathrm{s}$ (Campos et al., 1997).

También es importante indicar que en este inciso se consideran sólo las especies de hidrófitas acuáticas estrictas y subacuáticas.

Estación 1.

Embarcadero norte (Fig. 4).

Ubicación geográfica (UTM): 1490211862N, 2153123E.

Pendiente: $7.7 \%$.

Sustrato: textura areno-limosa, contenido de humedad $<45 \%$, contenido de materia orgánica $6 \%$, sin variaciones durante el año. Color pardo amarillento oscuro durante la temporada seca y pardo muy oscuro durante la temporada lluviosa.

Transparencia: durante la temporada seca $4 \mathrm{~m}$ y $2 \mathrm{~m}$ en la temporada lluviosa. Viento: Lf oeste 0 , Lf suroeste 0.09 , Lf sur 0.45 .

Número de especies de hidrófitas: 20.

Especies más abundantes: Nitella opaca, Potamogeton illinoensis y Panicum elephantipes.

Máxima profundidad de la vegetación: individuos aislados de Nitella opaca a $7.3 \mathrm{~m}$. Actividades humanas: agricultura y ganadería en las orillas del lago, acceso de embarcaciones con motor fuera de borda.

Observaciones: las hidrófitas enraizadas sumergidas se encontraron cubiertas de sedimento. Se han realizado esfuerzos locales con la construcción de presas de gaviones en los cerros colindantes, para disminuir los efectos de la erosión, aunque poco eficientes para resolver el problema (Fig. 5).

Estación 2.

Cabaña de Tembúcharo (Fig. 6).

Ubicación geográfica (UTM): 1490211605N, 2152221E.

Pendiente: $30 \%$.

Sustrato: textura areno-limosa, contenido de humedad $<45 \%$, contenido de materia orgánica $6 \%$, color pardo obscuro en la temporada seca y pardo muy oscuro durante la lluviosa. 
Pendiente promedio: $7.7 \%$
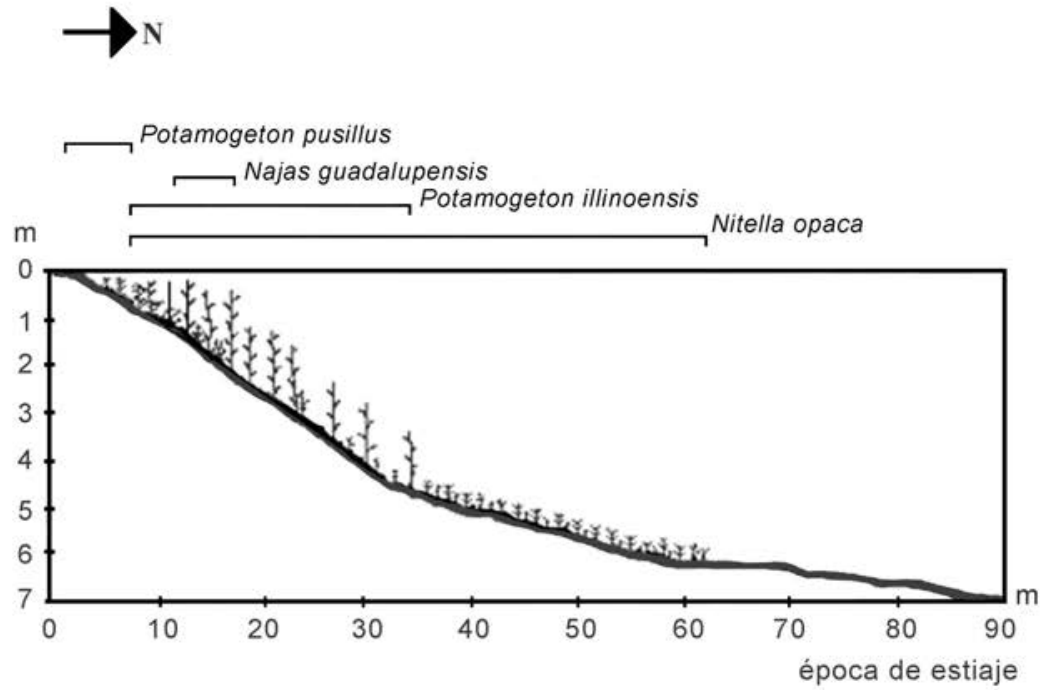

$\neg$ Cyperus spp.

$\neg$ Juncus spp.

$\neg$ Polygonum spp.

$\neg$ Hydrocotyle umbellata
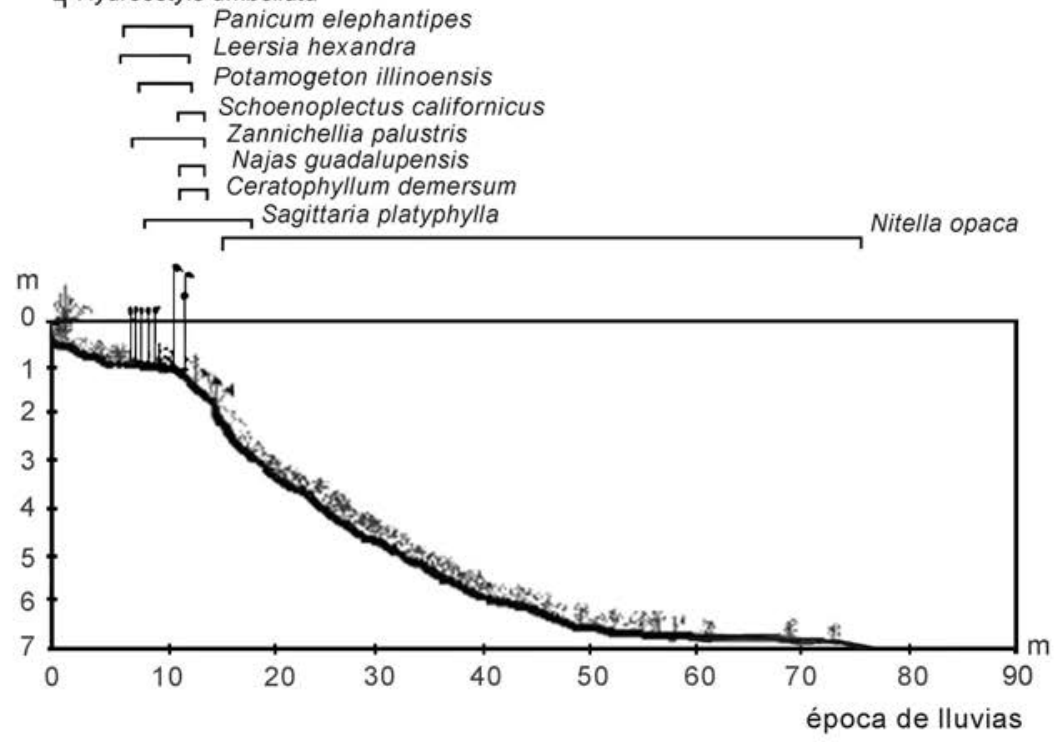

Fig. 4. Perfil diagramático de la distribución de las hidrófitas más frecuentes en el Embarcadero norte en época de estiaje y de lluvias (Est. No. 1). 


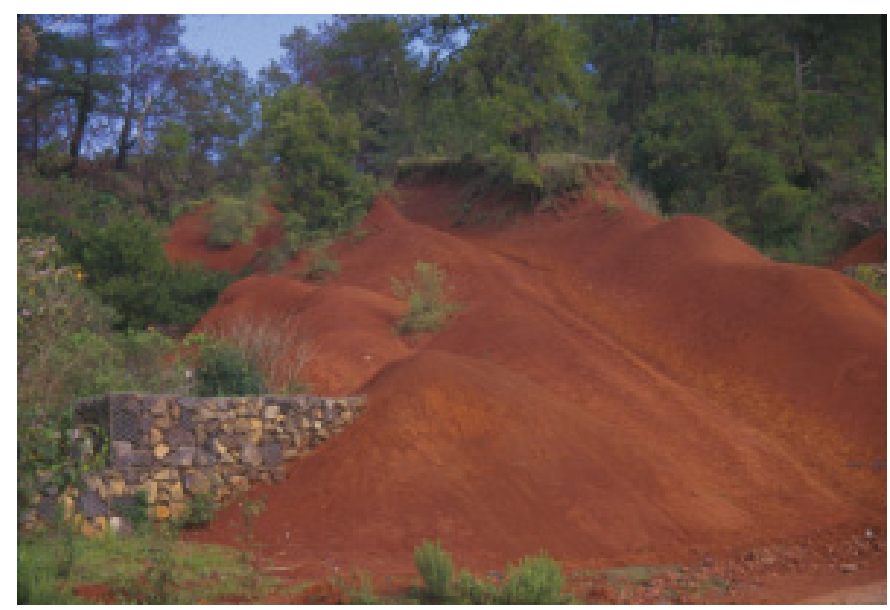

Fig. 5. Zonas altamente erosionadas a orillas de lago de Zirahuén, Michoacán, México.

Transparencia: $4.65 \mathrm{~m}$ en la temporada seca y 3.75 en la lluviosa.

Viento: Lf oeste 0, Lf suroeste 0.25 , Lf sur 0.46 .

Número de especies de hidrófitas: 12.

Especies más abundantes: Potamogeton illinoensis, Schoenoplectus californicus, Polygonum hydropiperoides, P. mexicanum y P. punctatum.

Máxima profundidad de la vegetación: Potamogeton illinoensis a $5.5 \mathrm{~m}$.

Actividades humanas: pesca.

Observaciones: bosque mesófilo de montaña, con escaso grado de deterioro a las orillas del lago.

Estación 3.

Área rocosa (Fig. 7).

Ubicación geográfica (UTM): 1490210454N, $2150760 \mathrm{E}$.

Pendiente: $50 \%$.

Sustrato: predominantemente rocoso; el sedimento con textura areno-limosa, contenido de humedad $<45 \%$, contenido de materia orgánica $12 \%$ en la temporada seca y $14 \%$ en la temporada lluviosa; de color pardo oscuro en la temporada seca y pardo grisáceo muy oscuro en la lluviosa.

Transparencia: $4.5 \mathrm{~m}$ en la temporada seca y 3.9 en la lluviosa.

Viento: Lf oeste 0, Lf suroeste 0, Lf sur 0.04.

Número de especies de hidrófitas: 3 .

Especies más abundantes: Potamogeton illinoensis y Nitella opaca.

Máxima profundidad de la vegetación: Nitella opaca a $13 \mathrm{~m}$.

Actividades humanas: ninguna. 
Pendiente promedio: $30 \%$

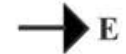

$\sqcap$ Hydrocotyle umbellata

$\longrightarrow$ Polygonum spp.

$\longrightarrow$ Najas guadalupensis

Schoenoplectus californicus
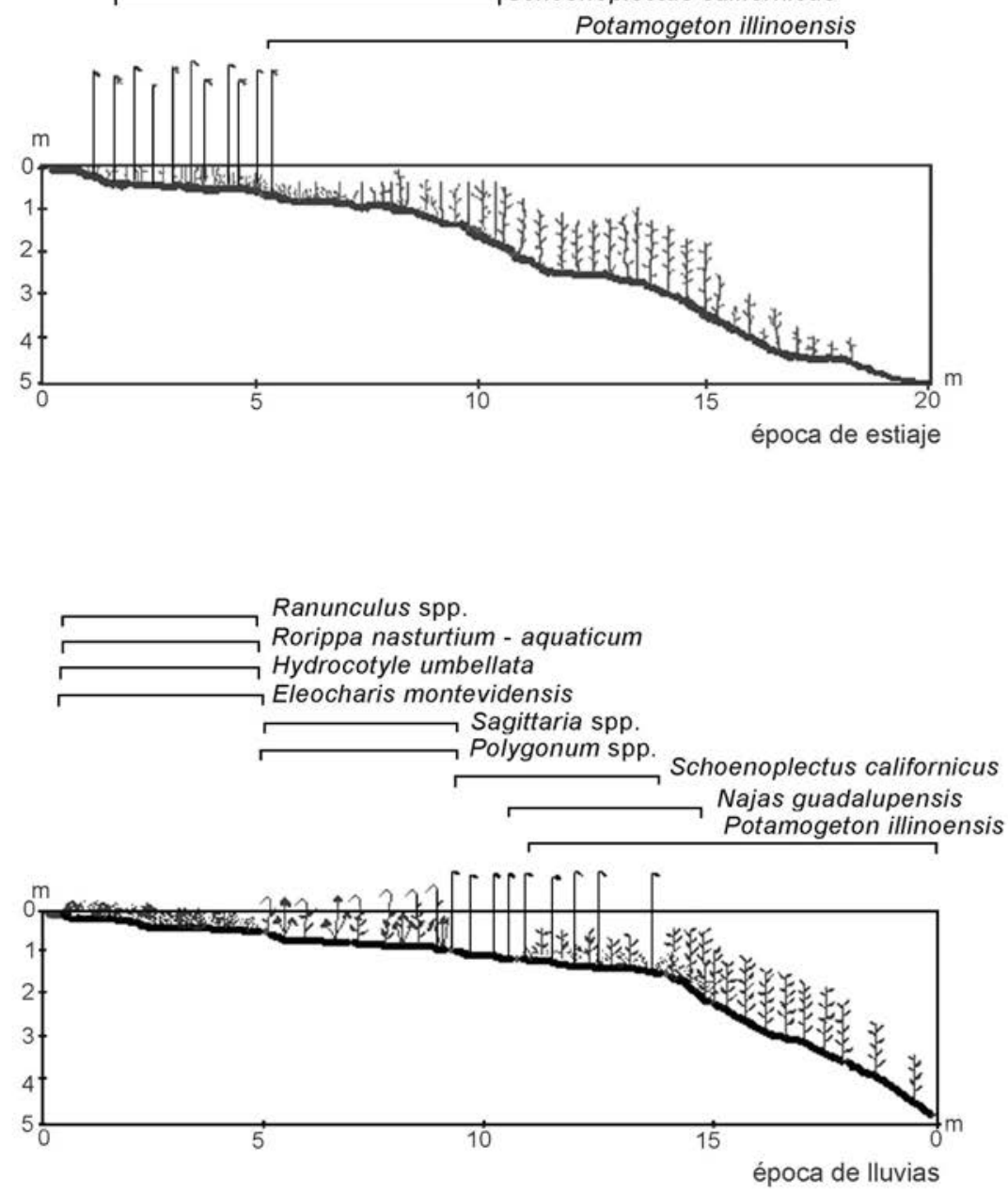

Fig. 6. Perfil diagramático de la distribución de las hidrófitas más frecuentes en la zona de Tembúcharo en época de estiaje y de lluvias (Est. No. 2). 
Pendiente promedio: $45 \%$
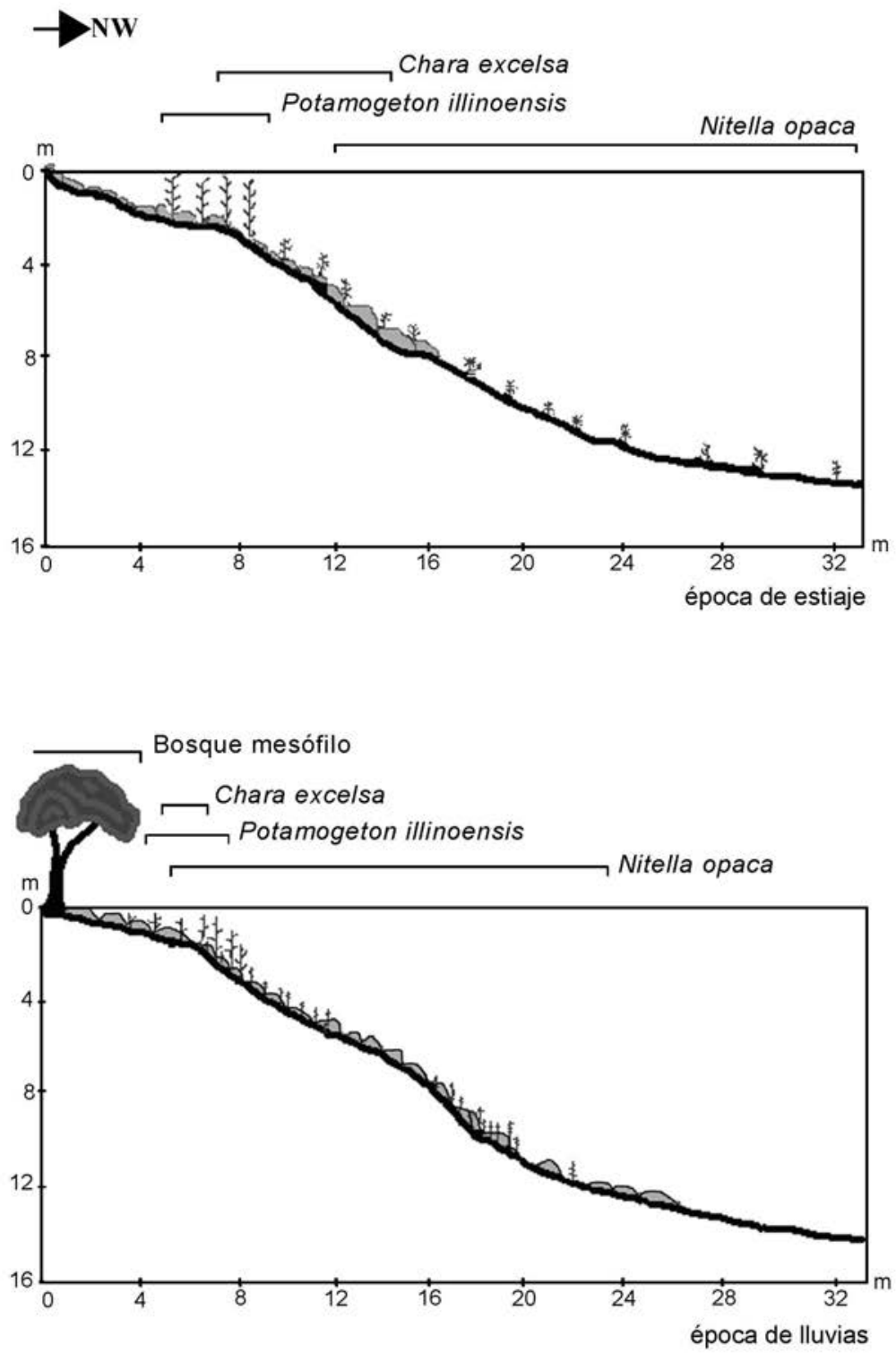

Fig. 7. Perfil diagramático de la distribución de las hidrófitas más frecuentes cerca de la costa de Copándaro en el área rocosa en época de estiaje y de lluvias (Est. No. 3). 
Observaciones: las hidrófitas sólo se establecen en los espacios entre las rocas, en los cuales ha sido posible la acumulación de sedimentos, en esta zona es donde se registraron las pendientes más pronunciadas del relieve.

\section{Estación 4.}

Islas (cara expuesta) (Fig. 8).

Ubicación geográfica (UTM): 1490211011N, 2149970E.

Pendiente: $40 \%$.

Sustrato: textura areno - limosa, contenido de humedad $<45 \%$, contenido de materia orgánica $10 \%$ durante la estación seca y $6 \%$ durante la temporada lluviosa; de color pardo oscuro durante todo el año.

Transparencia: $5.0 \mathrm{~m}$ durante la temporada seca y $3.9 \mathrm{~m}$ durante la lluviosa.

Viento: Lf oeste 0.02 , Lf suroeste 0 , Lf sur 0.

Número de especies de hidrófitas: 6.

Especies más abundantes: Chara excelsa y Potamogeton illinoensis.

Máxima profundidad de la vegetación: Nitella opaca a $11.8 \mathrm{~m}$.

Actividades humanas: pesca y turismo.

Observaciones: las islas están formadas por rocas volcánicas y una delgada capa de suelo, donde están presentes algunos elementos del bosque mesófilo. La separación entre las islas y la tierra firme es poco aparente, como consecuencia de la abundancia de Typha latifolia en las zonas de poca profundidad y sustrato suave. Asociadas a los tules se encuentran otras especies como Nymphoides fallax, Ludwigia palustris, Phragmites australis, Polygonum hydropiperoides y $P$. lapathifolium.

\section{Estación 5.}

Embarcadero de Agua Verde (Figs. 9a y 9b).

Ubicación geográfica (UTM): 1490211011N, 2149970E.

Pendiente: $6.6 \%$.

Sustrato: textura areno-limosa, contenido de humedad $<45 \%$, contenido de materia orgánica $12 \%$ en la temporada seca y $14 \%$ durante la lluviosa; de color pardo oscuro. Transparencia: $4.5 \mathrm{~m}$ durante la estación seca y 3.05 durante la lluviosa.

Viento: Lf oeste 0, Lf suroeste $0, \mathrm{Lf}$ sur 0.

Número de especies de hidrófitas: 17.

Especies más abundantes: Typha latifolia, T. domingensis, Potamogeton illinoensis y Chara excelsa.

Máxima profundidad de la vegetación: Chara excelsa a 7 m.

Actividades humanas: pesca y turismo.

Observaciones: único sitio en el lago donde se registró la presencia de Utricularia aff. macrorhiza, la cual se observó postrada sobre el fondo a una profundidad 
Pendiente promedio: $40 \%$
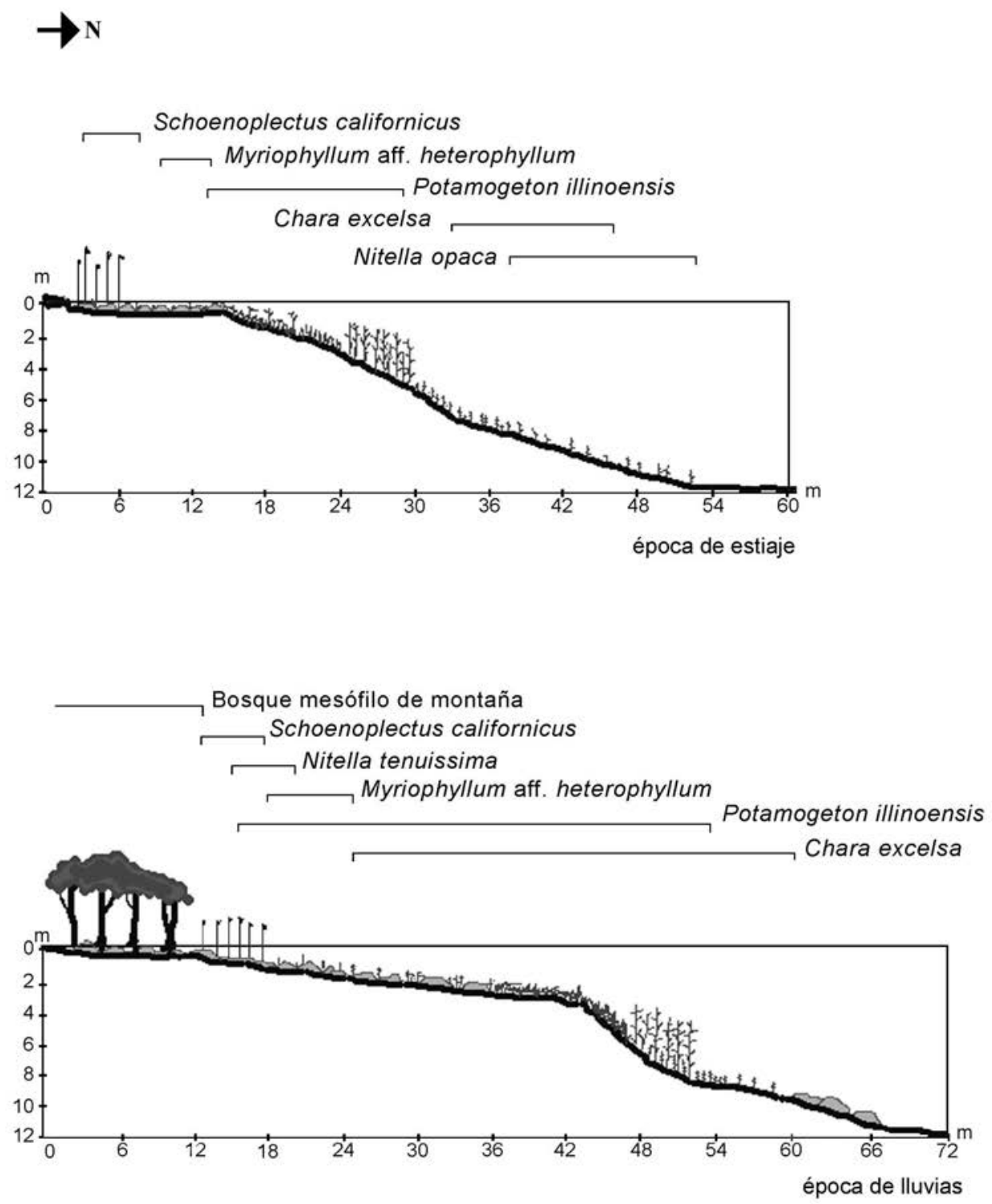

Fig. 8. Perfil diagramático de la distribución de las hidrófitas más frecuentes en las islas en época de estiaje y de lluvias (Est. No. 4). 
promedio de $2 \mathrm{~m}$. Es posible observar pequeños claros con algunos metros cuadrados de extensión entre las hidrófitas sumergidas, desprovistos de vegetación, como consecuencia de las actividades alimenticias de patos buceadores Aythya americana y Aythya vallisneria, que migran a este lago para alimentarse durante los meses de octubre a febrero.
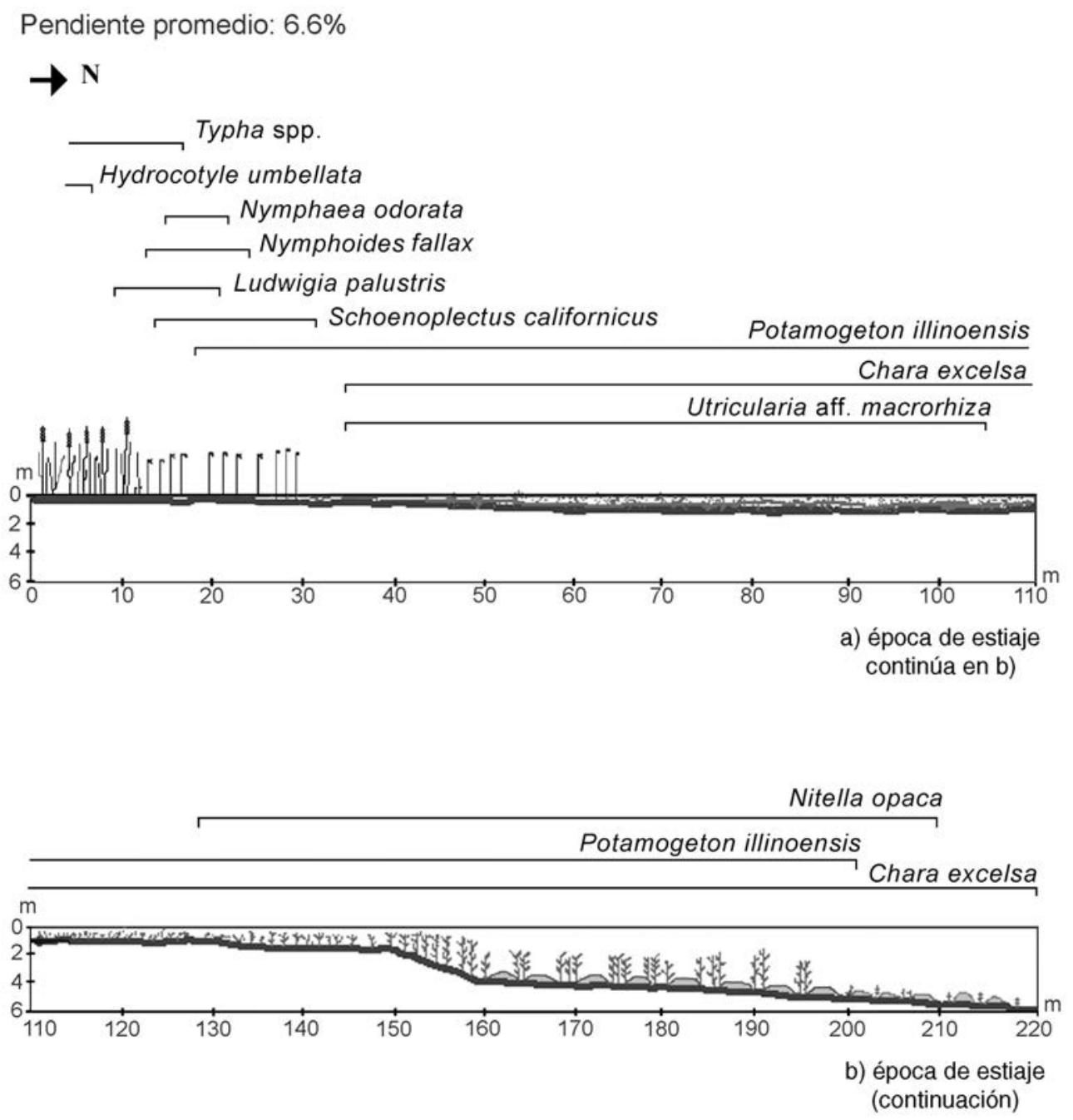

Fig. 9a y 9b. Perfil diagramático de la distribución de las hidrófitas más frecuentes en el Embarcadero de Agua Verde en época de estiaje y de lluvias (Est. No. 5). 
Estación 6.

Los Potreros (Fig. 10).

Ubicación geográfica (UTM): 1490212803N, 2149984E.

Pendiente: $17.5 \%$.

Sustrato: textura areno - limosa, contenido de humedad $<45 \%$, contenido de materia orgánica $8 \%$ en la estación seca y $6 \%$ durante la temporada lluviosa.

Transparencia: $4.5 \mathrm{~m}$ durante la estación seca y $3 \mathrm{~m}$ durante la lluviosa.

Viento: Lf oeste 0.27 , Lf suroeste 0 , Lf sur 0.

Número de especies de hidrófitas: 12.

Especies más abundantes: Potamogeton illinoensis, Polygonum mexicanum, $P$. punctatum, Cyperus odoratus y C. semiochraceus.

Máxima profundidad de la vegetación: Potamogeton illinoensis a $5 \mathrm{~m}$.

Actividades humanas: ganadería.

Observaciones: la vegetación frecuentemente presenta indicios de haber sido ramoneada por el ganado, incluso en algunos sitios dentro del agua con profundidades promedio a $0.5 \mathrm{~m}$.

\section{Estación 7.}

Desembocadura del río La Palma (Fig. 11).

Ubicación geográfica (UTM): 1490213767N, 2150185E.

Pendiente: $6.6 \%$.

Sustrato: textura areno-limosa, contenido de humedad $<45 \%$, contenido de materia orgánica $10 \%$ y color pardo grisáceo muy oscuro durante la estación seca y pardo muy oscuro durante la lluviosa.

Transparencia: $4 \mathrm{~m}$ durante la estación seca y $2.15 \mathrm{~m}$ en la lluviosa.

Viento: Lf oeste 0.41, Lf suroeste 0.07, Lf sur 0.04.

Número de especies de hidrófitas: 21.

Especies más abundantes: Potamogeton illinoensis, Cyperus niger, C. odoratus, C. semiochraceus, Polygonum hydropiperoides, P. mexicanum, P. punctatum, Sagittaria platyphylla y S. latifolia.

Máxima profundidad de la vegetación: Potamogeton illinoensis a $5 \mathrm{~m}$. Actividades humanas: agricultura y ganadería.

Observaciones: entre 5 y $7 \mathrm{~m}$ de profundidad es posible observar abundantes algas Charophyceae del género Lyngbya sobre el sustrato. En esta zona la línea de costa muestra desplazamientos considerables en algunos sitios (más de $50 \mathrm{~m}$ ), como consecuencia de las variaciones en el nivel del lago a lo largo del año. Aquí es donde mejor representadas se encuentran las hidrófitas enraizadas emergentes. 
Pendiente promedio: $17.5 \%$
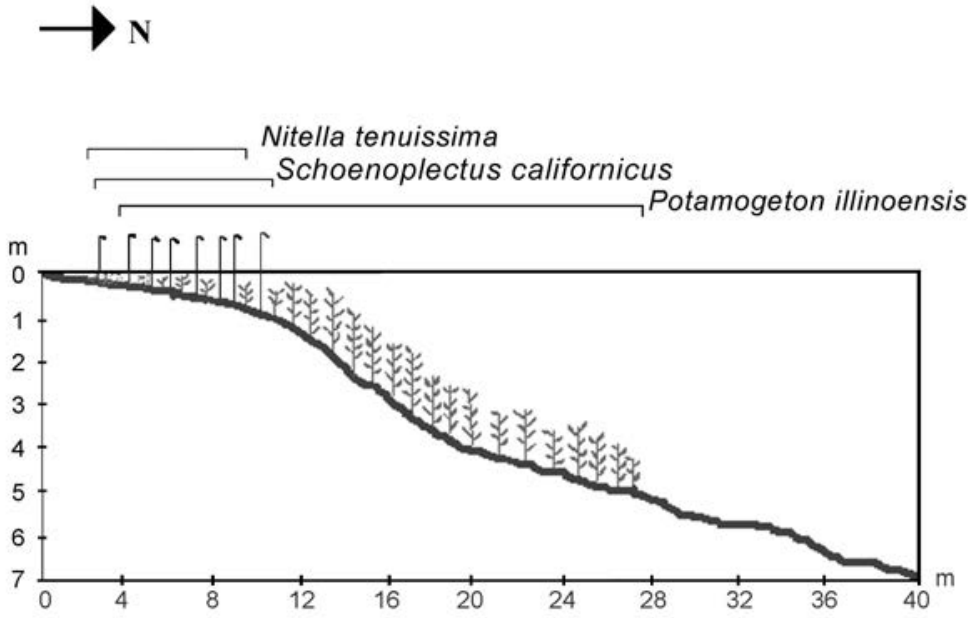

a) época de estiaje
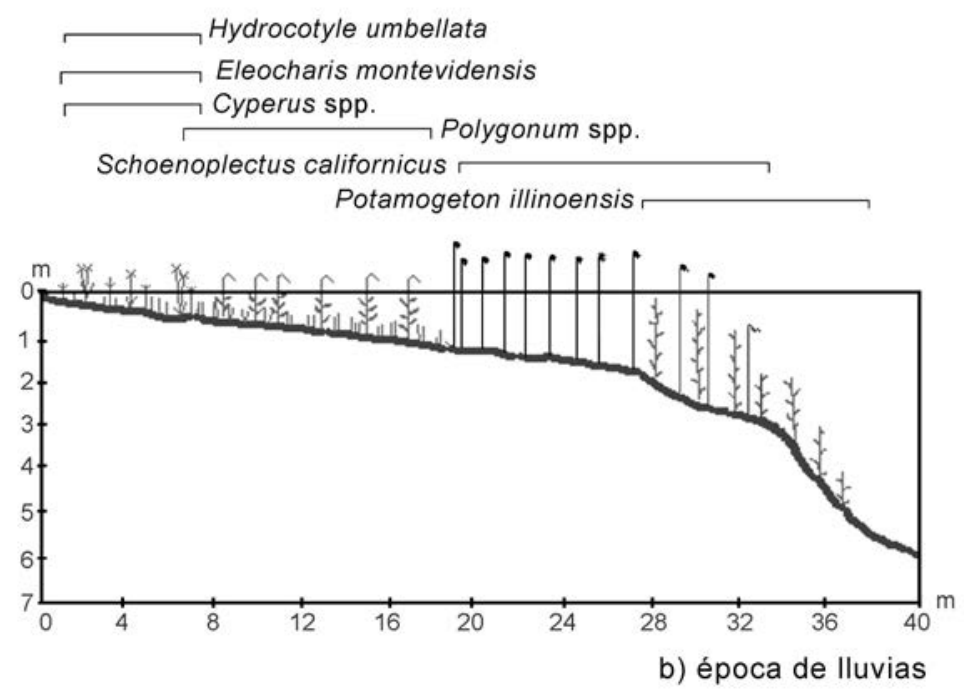

Fig. 10. Perfil diagramático de la distribución de las hidrófitas más frecuentes en Los Potreros en época de estiaje y de lluvias (Est. No. 6). 
Pendiente promedio: $6.6 \%$
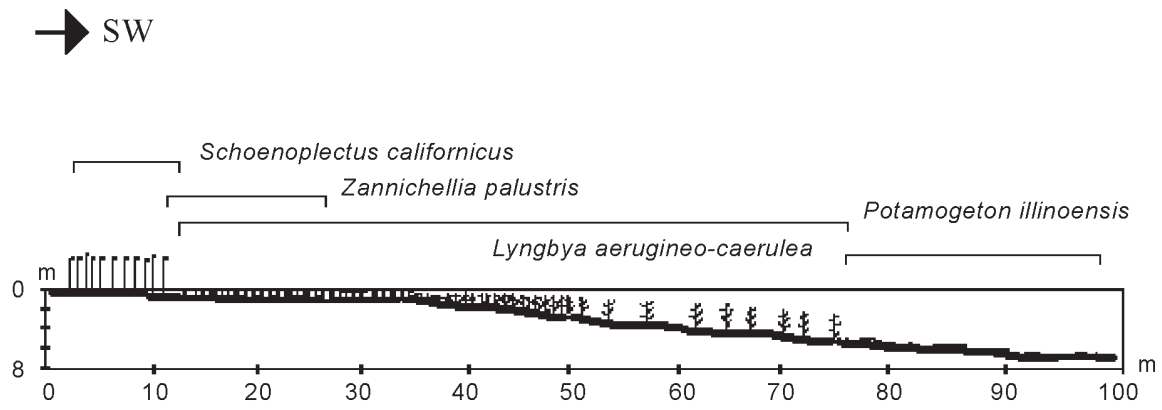

a) época de estiaje

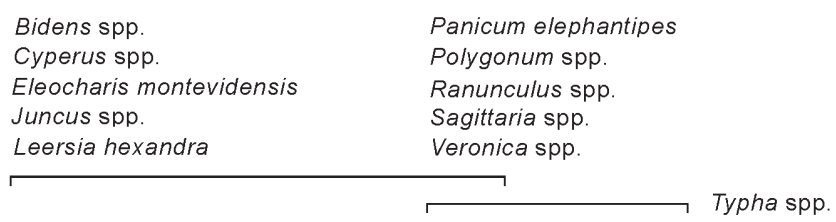

Schoenoplectus californicus

0

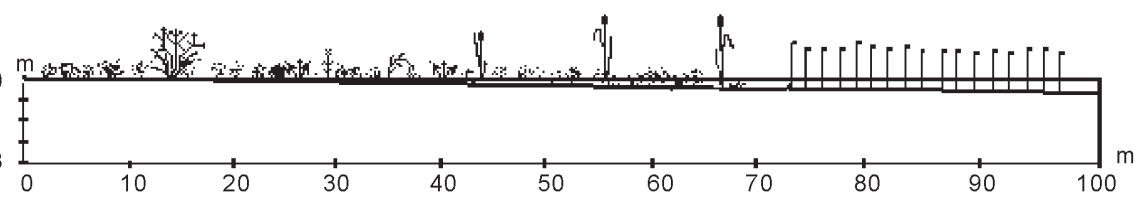

a) época de lluvias (continúa en b)

Potamogeton illinoensis

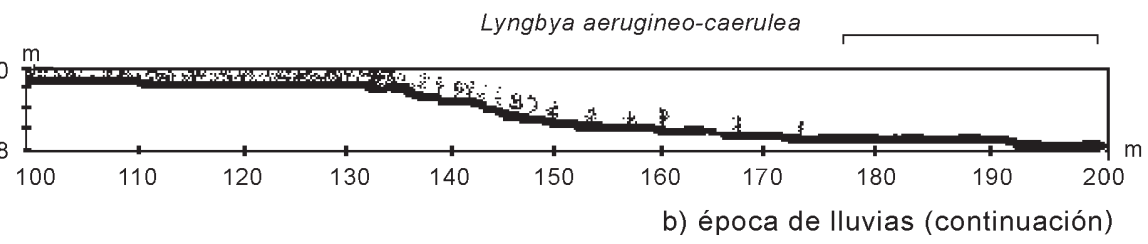

Fig. 11. Perfil diagramático de la distribución de las hidrófitas más frecuentes en la desembocadura del río La Palma en época de estiaje y de lluvias (Est. No. 7). 
Estación 8.

Cerrito Colorado (Fig. 12).

Ubicación geográfica (UTM): 1490213829N, 2151940E.

Pendiente: $11.4 \%$.

Sustrato: textura areno-limosa, contenido de humedad $<45 \%$, contenido de materia orgánica $6 \%$ y color pardo amarillento oscuro durante la estación seca y pardo grisáceo muy oscuro en la lluviosa.

Transparencia: $4.15 \mathrm{~m}$ durante la temporada seca y $3 \mathrm{~m}$ durante la de lluvias.

Viento: Lf oeste 0.44 , Lf suroeste 0.61 , Lf sur 0.45 .

Número de especies de hidrófitas: 9.

Especies más abundantes: Schoenoplectus californicus, Polygonum punctatum y $P$. hydropiperoides.

Máxima profundidad de la vegetación: Nitella opaca a 8 m.

Actividades humanas: pastoreo.

Observaciones: es la zona del lago que recibe la mayor influencia de los vientos y corrientes superficiales.

Influencia de los factores ambientales sobre la vegetación

Los factores ambientales presentan mayor o menor influencia sobre la vegetación en cada uno de los sitios, sin embargo, la pendiente es el elemento que muestra la relación más clara respecto a la cantidad de especies de hidrófitas acuáticas estrictas y subacuáticas en las estaciones de muestreo. Esta relación puede observarse en la gráfica riqueza/pendiente (Fig. 13), en donde se aprecia que el número de especies presentes en cada una de las estaciones disminuye de manera proporcional a medida que se incrementa el declive. El coeficiente de correlación estimado tiene un valor de $\mathrm{r}=-0.858$, el cual muestra una estrecha relación inversa entre los valores de la riqueza y la pendiente. La reducción del número de especies es consecuencia de la disminución en la amplitud de la zona litoral y el drástico incremento en la profundidad en las zonas de inclinación pronunciada, lo cual limita de esta forma las áreas en las cuales puede establecerse la vegetación.

La vegetación acuática creció a mayor profundidad en los sitios en donde hubo una mayor transparencia promedio a lo largo del año. Estas áreas se ubican en la zona suroeste del lago, en las estaciones 3 y 4. Las hidrófitas alcanzaron una profundidad de $13 \mathrm{~m}$ y $11.8 \mathrm{~m}$ respectivamente. Por el contrario, la zona con menor transparencia fue la estación 7, ubicada en las proximidades de la desembocadura del río La Palma con un valor máximo de $5 \mathrm{~m}$ de profundidad (Fig. 14). La profundidad de establecimiento y la transparencia muestran una relación directa existente entre ambos factores, para la que se obtuvo un coeficiente de correlación de $r=0.570$, que a pesar de no ser un valor alto, demuestra que al aumentar la 
Pendiente promedio: $11.4 \%$
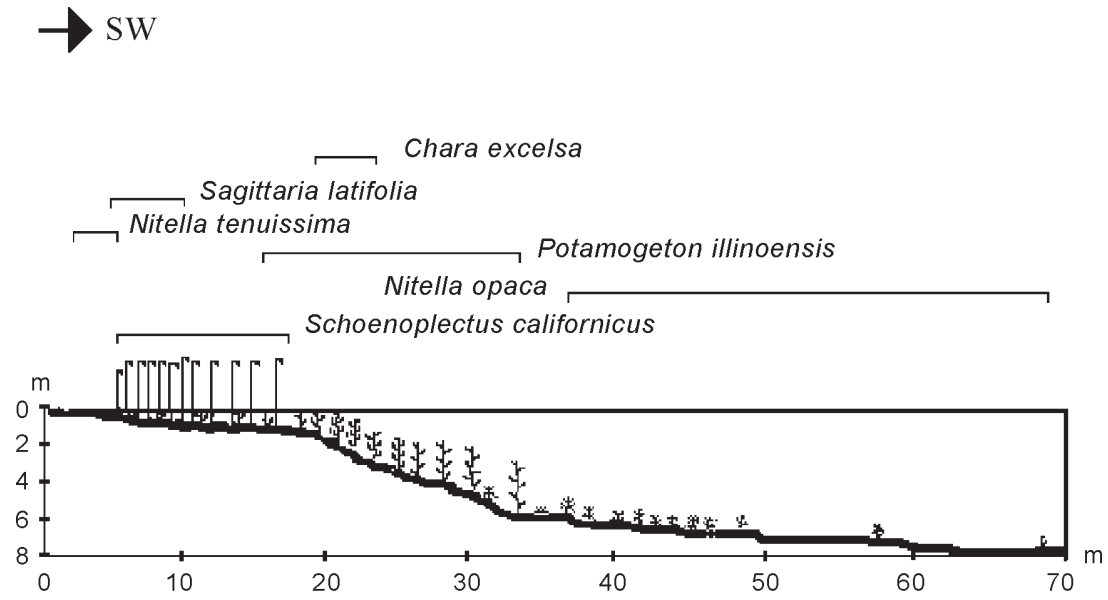

a) época de estiaje
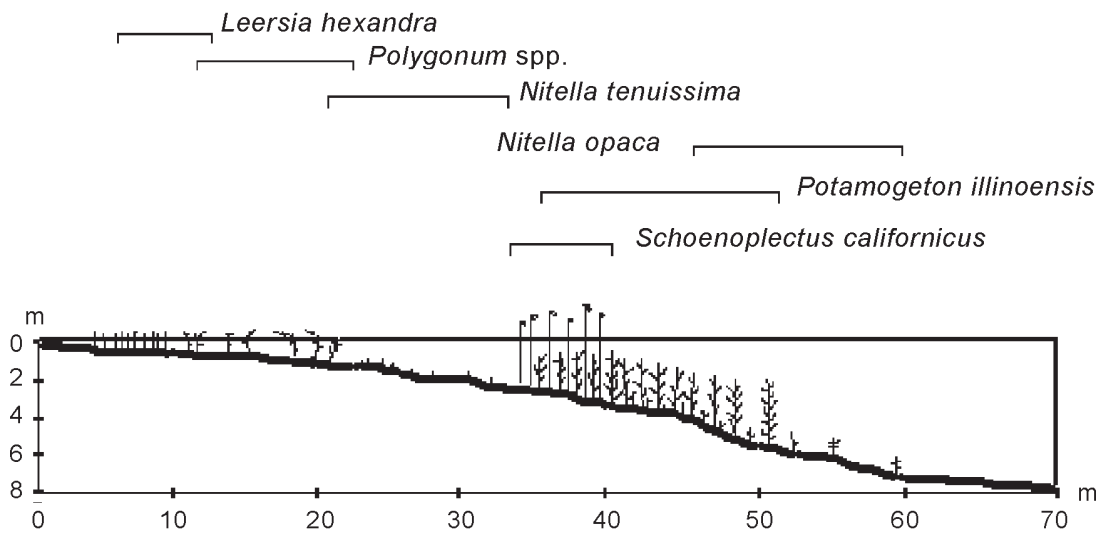

b) época de lluvias

Fig. 12. Perfil diagramático de la distribución de las hidrófitas más frecuentes en Cerrito Colorado en época de estiaje y de lluvias (Est. No. 8). 


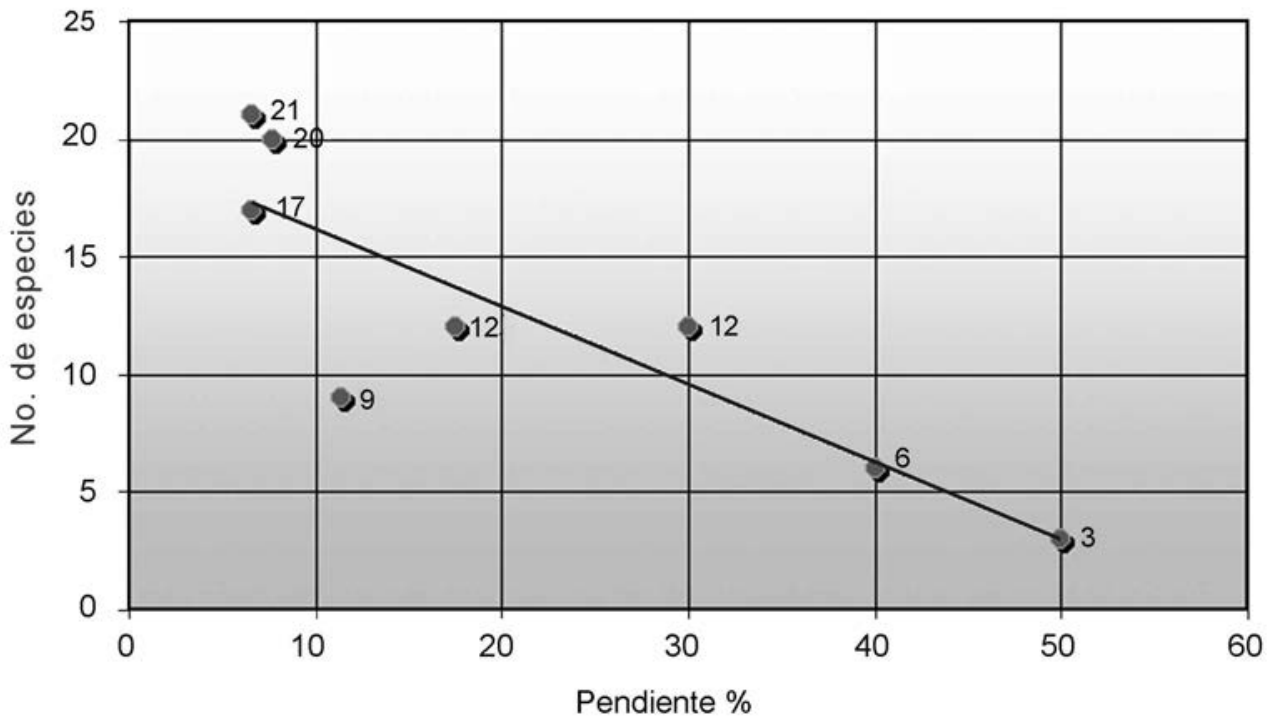

Fig. 13. Número de especies con relación a las diferentes pendientes de la zona litoral en el lago de Zirahuén, Michoacán, México.

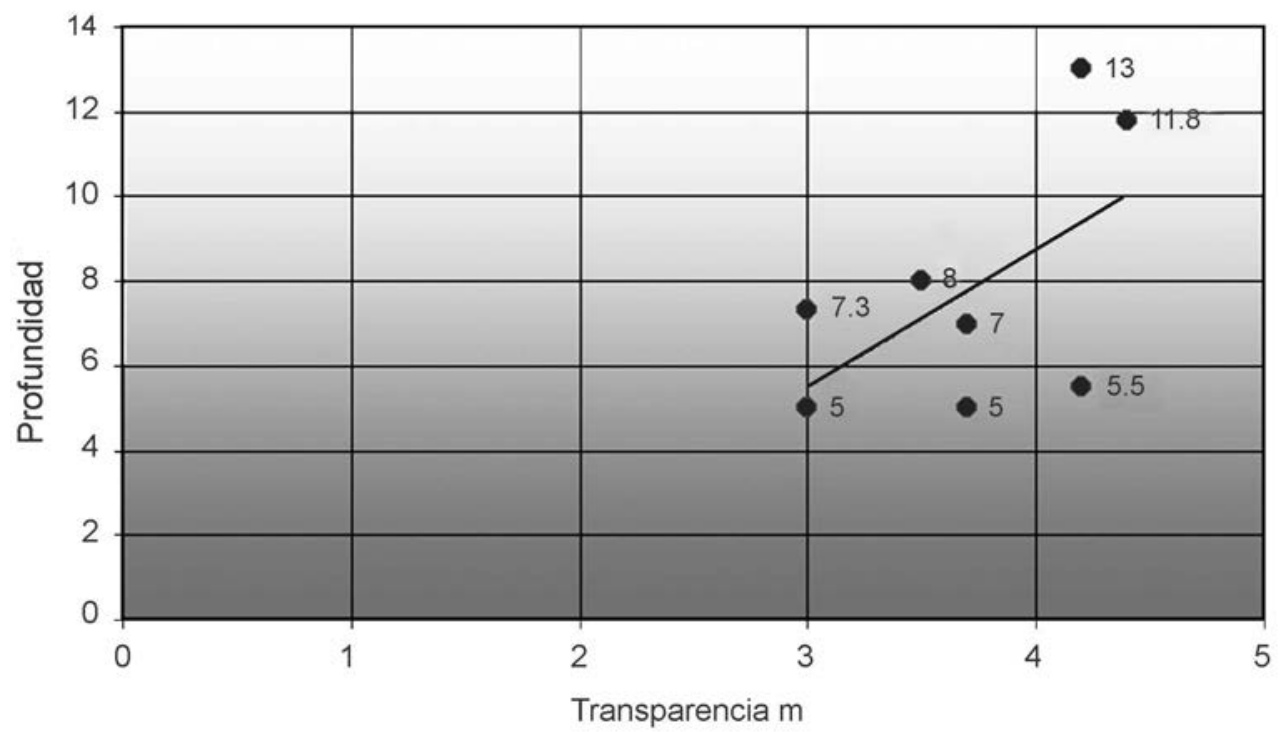

Fig. 14. Máxima profundidad de establecimiento de la vegetación con relación a la transparencia del disco de Secchi, en el lago de Zirahuén, Michoacán, México. 
transparencia se incrementa de forma directa la profundidad a la cual le es posible establecerse a la vegetación acuática.

El número de especies y formas de vida disminuye al aumentar la profundidad (Fig. 15). Los valores obtenidos al calcular los coeficientes de correlación para el número de especies y número de formas de vida fueron de $\mathrm{r}=-0.695$ y $\mathrm{r}=-0.696$ respectivamente, ambos similares y mostrando la influencia inversa y significativa que presenta la profundidad sobre el establecimiento de las comunidades de hidrófitas.

El sustrato areno-limoso a lo largo de toda la zona litoral permite el establecimiento y desarrollo adecuado de la vegetación y solamente en las zonas correspondientes a las estaciones 3 y 4, donde existen áreas cubiertas por rocas, las hidrófitas no prosperan en forma continua, ya que solamente se encuentran en las superficies libres de rocas, o bien en los sitios donde se ha acumulado suficiente sedimento para permitir su colonización.

La incidencia del viento posee diferentes direcciones a lo largo del año con los valores siguientes: oeste 2\%, suroeste 67\% y sur 31\% (Campos et al. 1997), por lo que las zonas que reciben la mayor influencia se encuentran en la parte noreste del lago, correspondiente a la estación 8 . No obstante que esta localidad presenta pendiente suave, sustrato blando y extensas áreas someras, posee escasa diversidad de especies. A su vez, las estaciones 3 y 5 se encuentran protegidas de la influencia de los vientos, aunque como consecuencia de la pendiente pronunciada y la abundancia de rocas en la estación 3 la vegetación es escasa. Por el contrario, la estación 5, además de estar protegida, presenta extensas áreas someras, sustrato blando y pendiente suave, condiciones favorables para el desarrollo de las plantas. La gráfica que ilustra la relación riqueza de especies y vientos (Fig. 16) muestra escasa influencia de este factor sobre las comunidades de hidrófitas, ya que el coeficiente de correlación obtenido posee un valor poco significativo con $r=0.097$. Esto probablemente es consecuencia de la mayor influencia que tiene el tipo de sustrato en el establecimiento de la vegetación. Así descuella la escasa riqueza de la zona suroeste, en particular para la estación 3 en donde la influencia de los vientos es escasa, pero el sustrato es predominantemente rocoso y la pendiente pronunciada. Por el contrario, la estación 7 en la zona este del lago recibe una mayor influencia del viento, sin embargo la diversidad de especies es notablemente mayor.

Las acciones humanas con impacto negativo sobre la vegetación son la agricultura y la ganadería a las orillas del lago, ya que son responsables del deterioro de las zonas donde se establece la misma. Los efectos más aparentes ocasionados por estas actividades se presentan en las estaciones 1 y 6 . Las estaciones 2, 3, 4 y 5 ubicadas en zonas del lago, donde los aprovechamientos humanos se limitan principalmente a la pesca y al turismo, presentan un deterioro menos marcado. 
Madrigal et al: Flora y Vegetación Acuáticas del Lago de Zirahuén

Spp. / Profundidad $r=-0.695$ Forma de vida / profundidad $r=-0.696$

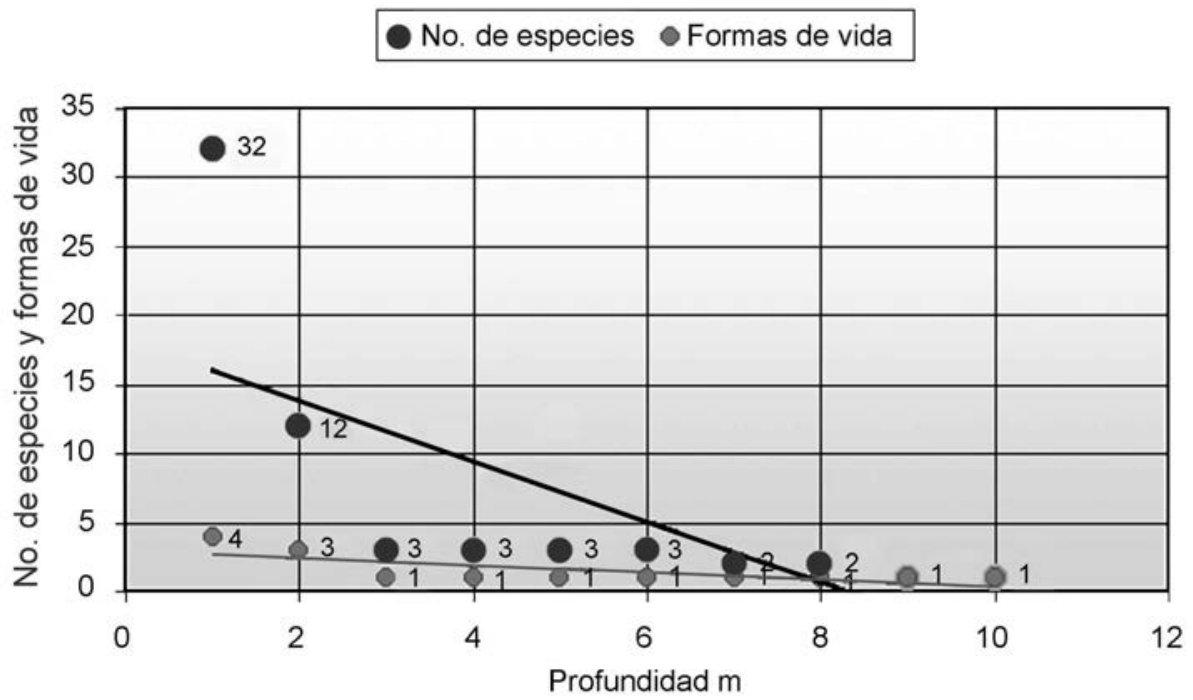

Fig. 15. Número de especies y formas de vida en función de la profundidad, en el lago de Zirahuén, Michoacán, México.

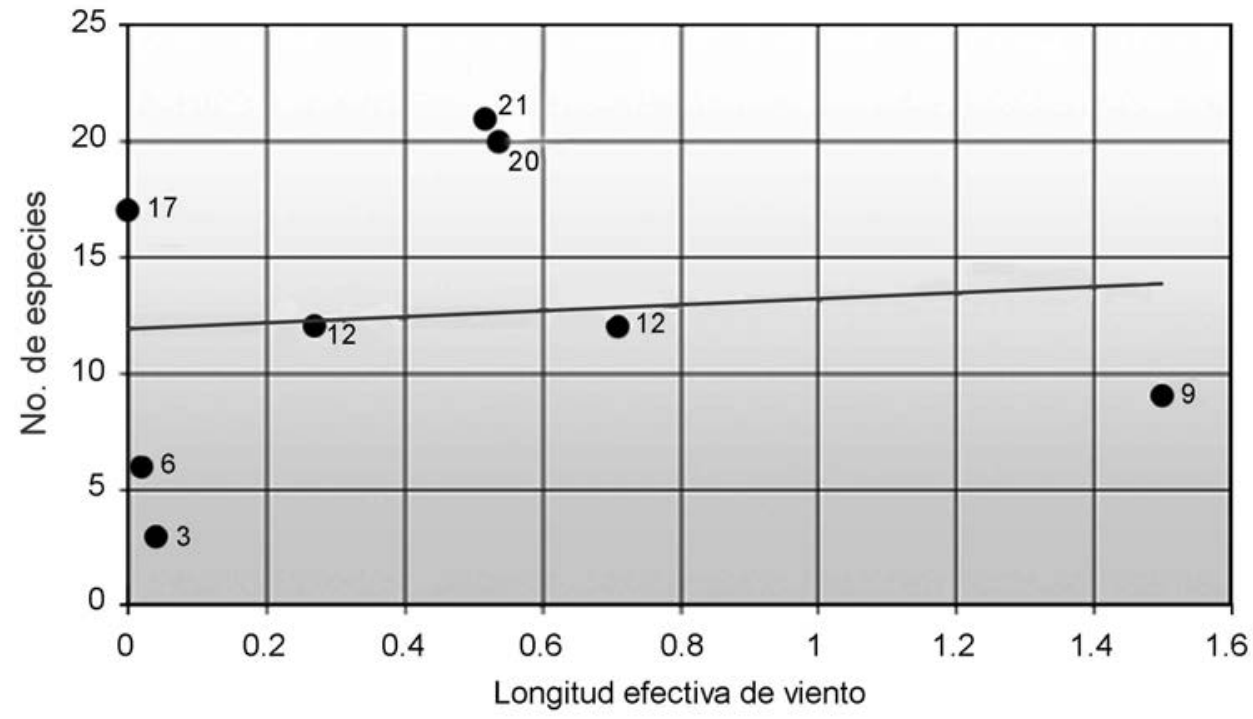

Fig. 16. Número de especies con relación a la influencia del viento, en el lago de Zirahuén, Michoacán, México. 
Flora

No obstante su extensión relativamente reducida, el lago de Zirahuén posee numerosas variantes ambientales a lo largo de la línea de costa y zona litoral como consecuencia de las variaciones en la pendiente, en los tipos de sustratos y en la de calidad del agua, presentando diferentes tipos de hábitats. De esta manera, se integran las condiciones favorables para el establecimiento de diversas asociaciones vegetales, lo cual se refleja en la riqueza florística, formada por 35 familias, 55 géneros y 93 especies.

Las familias mejor representadas son: Cyperaceae, con cinco géneros y 14 especies, entre los que destacan Cyperus, Eleocharis y Schoenoplectus, de las Scrophulariaceae se localizan seis géneros, destacando Bacopa, Mimulus, Pedicularis y Veronica, este último con el mayor número de componentes. De la familia Polygonaceae solamente se registra Polygonum, con cinco especies en el lago.

Es importante mencionar que en este trabajo se incluyeron tres distintas macroalgas, debido a su constante presencia y las amplias superficies que cubren. Las algas microscópicas no fueron estudiadas.

Un aspecto importante con relación a las especies de hidrófitas registradas en el lago de Zirahuén, es que ninguna de ellas es considerada maleza acuática, lo cual refleja el estado de la calidad del agua. En particular, destaca la ausencia de lirio acuático Eichhornia crassipes, cuya abundancia en los lagos de Pátzcuaro y Cuitzeo ha sido causa de serios problemas. Una planta adventicia en la región de estudio, procedente de Europa, es Rorippa nasturtium-aquaticum, la que probablemente fue introducida por el hombre, ya que es apreciada como alimento por los pobladores de la zona. Por otra parte, es de enfatizar la presencia en el lago de Zirahuén de especies actualmente poco frecuentes en muchos de los cuerpos de agua del estado, debido a las condiciones ambientales particulares que se requieren para su establecimiento y desarrollo. Así Potamogeton amplifolius, Nymphaea odorata, Utricularia aff. macrorhiza, Chara excelsa y Nitella opaca entre otras, confirman la diversidad ecológica existente, con zonas de aguas transparentes, pendientes suaves, escasa influencia del oleaje y sustrato suave.

El listado florístico del lago de Zirahuén se encuentra en un apéndice al final del trabajo.

Afinidades fitogeográficas

La flora acuática estudiada posee elementos de afinidad boreal, neotropical, de amplia distribución en el continente americano y cosmopolitas, principalmente. No existe ningún registro de hidrófitas endémicas a la localidad, aunque cabe mencionar que el lago de Zirahuén es el único sitio en nuestro país en donde existe Potamogeton 
amplifolius. La principal relación geográfica de la flora se presenta hacia el norte con un total de 44 especies de afinidad boreal, siendo éste el grupo más numeroso. De ellas, 10 son endémicas a México y cinco han sido introducidas. La relación fitogeográfica hacia el sur con elementos de afinidad neotropical está representada por 12 elementos. Están presentes 10 especies que se encuentran ampliamente distribuidas a lo largo del continente americano. El grupo de cosmopolitas queda integrado por 11 elementos y sólo una de las registradas posee relación con el continente africano.

Dentro del conjunto constituido por especies de afinidad boreal, destacan por su amplia distribución en el lago Chara excelsa, Nitella opaca y las especies del género Sagittaria. Las de afinidad neotropical mejor representadas son Leersia hexandra y Panicum elephantipes. Entre los elementos ampliamente distribuidos en América se encuentran los componentes del género Hydrocotyle y Potamogeton illinoensis. Las especies cosmopolitas de mayor importancia en el lago pertenecen a los géneros Typha y Ludwigia.

Con base en el número de taxa correspondiente a cada uno de los grupos, es posible apreciar que las especies presentes en el lago poseen una mayor semejanza florística con las regiones templadas y frías del hemisferio boreal, particularmente con los Estados Unidos de América y Canadá. Lo anterior puede interpretarse como consecuencia de la colindancia directa con esta región y la altitud a la cual se encuentra Zirahuén, que propicia la existencia de condiciones climáticas adecuadas para el establecimiento de plantas de afinidad boreal.

El Cuadro 1 muestra el número de elementos que conforman a cada uno de los grupos formados con base en las afinidades geográficas de las especies; asimismo se indica el porcentaje que representa cada uno.

\section{DISCUSIÓN Y CONCLUSIONES}

El lago de Zirahuén posee una gran diversidad de ambientes a lo largo de su línea de costa y zona litoral, lo cual crea condiciones ecológicas muy heterogéneas, permitiendo el establecimiento de una flora acuática variada.

Las comunidades de hidrófitas se encuentran distribuidas a manera de una franja angosta a lo largo de la orilla del lago, presentando diferentes formas de vida, las cuales prosperan en función de la profundidad y las condiciones ambientales específicas de cada sitio, proporcionadas principalmente por la transparencia del agua y tipo de sustrato. En las áreas de pendiente pronunciada y de tipo rocoso, la amplitud de la zona litoral y su cubierta vegetal es escasa, mientras que en los sitios con poca pendiente y sustrato areno-limoso, la vegetación puede cubrir grandes extensiones, presentando una mayor diversidad y diferentes formas de vida. 
Cuadro 1. Afinidades geográficas de la flora del lago de Zirahuén, Michoacán, México.

\begin{tabular}{|l|c|c|}
\hline \multicolumn{1}{|c|}{ Afinidad } & No. de Especies & Porcentaje \\
\hline Boreal & 44 & 47.3 \\
\hline Endémicas a México & 10 & 10.7 \\
\hline Neotropical & 12 & 12.9 \\
\hline Ampliamente distribuidas en América & 10 & 11.8 \\
\hline Cosmopolitas & 11 & 1.0 \\
\hline Africana & 1 & 5.3 \\
\hline Introducidas & 5 & \\
\hline
\end{tabular}

La baja transparencia del agua se registra en los lugares más afectados por el proceso de erosión del suelo y el aporte de sedimentos por los afluentes. Este fenómeno, aunado al incremento de las concentraciones de clorofila $\alpha$, consecuencia del proceso de eutroficación que experimenta el lago por las actividades humanas (como lo muestran los estudios de Chacón y Múzquiz (1991)), limita el desarrollo de las comunidades de hidrófitas enraizadas sumergidas, ya que reduce la penetración de la luz y favorece la acumulación de sólidos sobre sus hojas. De continuar la actual marcha de deterioro, tales agrupaciones vegetales probablemente se verán desplazadas a zonas más someras donde puedan disponer de luz suficiente para su desarrollo. Por el contrario, la acumulación de sedimentos ricos en nutrientes y la creación de áreas poco profundas como consecuencia del azolve, podrían favorecer el desarrollo de extensas comunidades de hidrófitas enraizadas emergentes, en donde actualmente existen las enraizadas sumergidas, acelerando el proceso de sucesión.

El manejo inadecuado de los bosques y el cambio del uso del suelo son los principales factores responsables del deterioro de los recursos de la cuenca y del lago, afectando de forma directa a las comunidades de hidrófitas, en particular a 
las enraizadas sumergidas al reducir la profundidad de la zona eufótica por la llegada de sedimentos al cuerpo lacustre.

Algunas de las especies presentes en el lago de Zirahuén, dada su distribución restringida en nuestro país, así como las condiciones ambientales particulares que requieren para su desarrollo, han sido incluidas en la Norma Oficial Mexicana -059ECOL-2001, bajo diferentes categorías de riesgo. Nymphaea odorata aparece en calidad de amenazada y Potamogeton amplifolius se encuentra ubicada en la clase de protección especial. Lo anterior hace evidente la necesidad de tomar medidas de ordenamiento y conservación encaminadas a preservar este ecosistema y sus especies.

Al someter los géneros registrados de hidrófitas acuáticas y subacuáticas que comparten los lagos de Zirahuén, Cuitzeo (Rojas y Novelo, 1995) y Pátzcuaro (García, 1990) a un análisis de grupos, el valor obtenido fue de 0.504 y el que se registró al comparar estos dos últimos lagos fue de 0.697. Así se observa que a pesar de ser cuerpos de agua próximos con cuencas colindantes, como consecuencia de la heterogeneidad de factores ambientales existentes a lo largo de la zona litoral de las tres entidades lacustres, así como su estado trófico y profundidad, en cada caso prevalecen condiciones ecológicas particulares que se reflejan en la composición florística de su vegetación (Fig. 17).

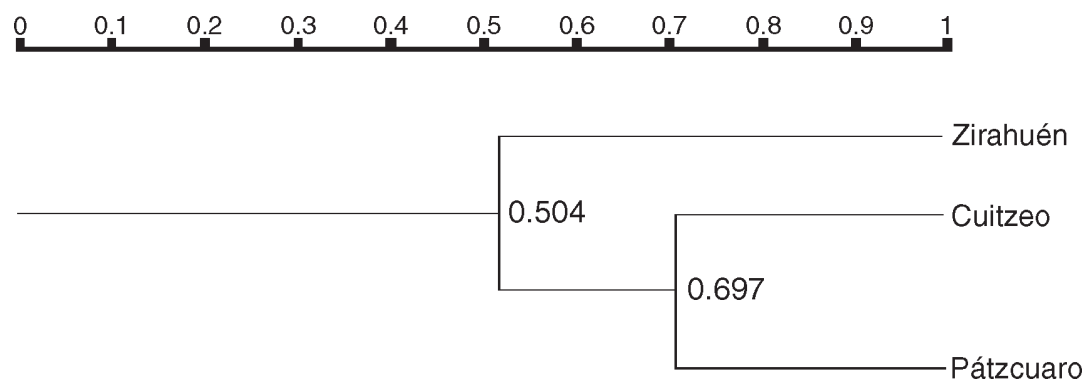

Fig. 17. Dendrograma de análisis de grupos (cluster) aplicado para comparar la composición florística de la vegetación de los lagos de Zirahuén, Pátzcuaro y Cuitzeo, Michoacán, México.

Por lo anterior, es evidente la necesidad de tomar las medidas adecuadas a corto y largo plazo para contrarrestar y evitar que continúe el actual proceso de deterioro, mediante acciones encaminadas a la conservación y el aprovechamiento racional de los recursos bióticos y abióticos de toda la cuenca (Fig. 18). 


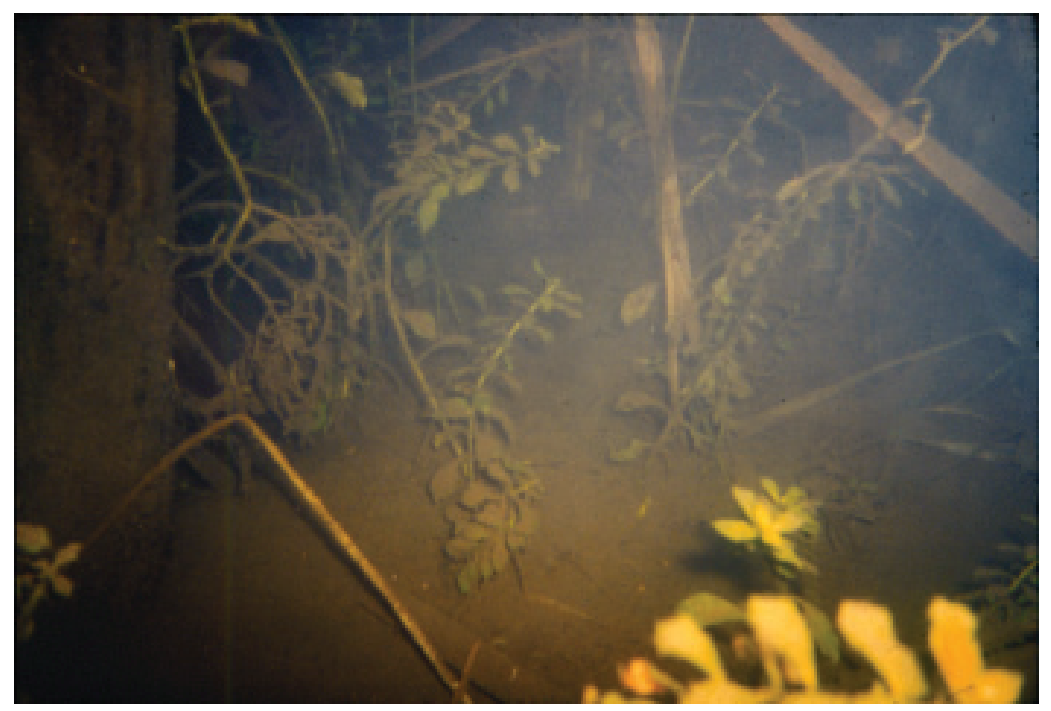

Fig. 18. Hidrófitas enraizadas sumergidas a $1.5 \mathrm{~m}$ de profundidad con la superficie de sus hojas cubiertas por sedimentos, consecuencia del alto acarreo de terrígenos al lago por la erosión.

\section{AGRADECIMIENTOS}

Deseamos agradecer al personal del Departamento de Botánica del Instituto de Biología de la Universidad Nacional Autónoma de México, del Instituto de Investigaciones sobre los Recursos Naturales de la Universidad Michoacana de San Nicolás de Hidalgo y al Centro Regional del Bajío del Instituto de Ecología, A. C., por su valiosa colaboración en la realización de este trabajo. Igualmente se debe reconocimiento al Biól. Omar Domínguez Domínguez, al M.C. Antonio Campos Mendoza y al Lic. Francisco Rangel Huacuz por su substancial ayuda en la realización de las colectas y del trabajo de campo.

\section{LITERATURA CITADA}

Anónimo. 1985. Síntesis geográfica del estado de Michoacán. Secretaría de Programación y Presupuesto. México, D.F. 316 pp.

Antaramián H., E. y J. M. Ortega, R. 1996. Riesgo de erosión en la cuenca de Zirahuén, cambios de área y volumen en el lago. Ciencia Nicolaita; Morelia, Mich. 11: 83-94. Brown, A. L. 1976. Ecology of fresh water. Heineman Educational Books. Londres. 129 pp. 
Campos, M. A., H. A. Gutiérrez y D. I. Hernández. 1997. Limnología física del lago de Zirahuén, Michoacán, México. Tesis Profesional. Facultad de Biología, Universidad Michoacana de San Nicolás de Hidalgo. Morelia, Mich. 97 pp.

Chacón T., A. y E. Múzquiz I. 1991. El Lago de Zirahuén, Michoacán, México. Reconocimiento ambiental de una cuenca michoacana. Universidad Michoacana de San Nicolás de Hidalgo. Morelia, Mich. 30 pp.

Chacón T., A. y C. Rosas-Monge. 1998. Water quality characteristics of a high altitude oligotrophic Mexican lake. Aquatic Ecosystem Health and Management Society 1:237-243.

Chambers, P. y J. Kalff. 1985. Depth distribution and biomass of submersed aquatic macrophyte communities in relation to Secchi depth. Can. J. Fish. Aquat. Sci. 42: 701709.

Cronquist, A. 1981. An integrated system of classification of flowering plants. Columbia University Press. Nueva York. 1262 pp.

García A., L. C. 1990. Flora vascular acuática y semiacuática del Lago de Pátzcuaro, Michoacán, México. Tesis Profesional. Facultad de Biología, Universidad Michoacana de San Nicolás de Hidalgo. Morelia, Mich. 103 pp.

Hakanson, L. 1981. A manual of lake morphometry. Springer-Verlag, Berlin. Heidelberg. Nueva York. 75 pp.

Ikushima, I. 1987. Productivity and potential uses of macrophytes. Arch. Hydrobiol. Beih. Ergebn. Limnol. 28: 221-225.

Israde, A. I. 1999. Los lagos volcánicos y tectónicos de Michoacán. Carta geológica de Michoacán. Instituto de Investigaciones Metalúrgicas. Universidad Michoacana de San Nicolás de Hidalgo. Morelia, Mich. pp. 46-74.

Kaul, V. y S. Kaul. 1987. A bibliography to macrophytes as components of aquatic ecosystems in tropical inland waters. Arch. Hydrobiol. Beih. Ergebn. Limnol. 28: 213219.

Lot H., A. y Novelo R., A. 1988. Vegetación y flora acuática del lago de Pátzcuaro, Michoacán, México. Southwestern Naturalist 33(2): 167-175.

Lot H., A., A. Novelo R., M. Olvera G. y P. Ramírez G. 1999. Catálogo de angiospermas acuáticas de México. Cuadernos 33. Instituto de Biología, Universidad Nacional Autónoma de México. México. D.F. 161 pp.

Norma Oficial Mexicana NOM-059-ECOL-2001. Protección ambiental. Especies nativas de México de flora y fauna silvestres. Categorías de riesgo y especificaciones para su inclusión, exclusión o cambio. Lista de especies en riesgo. Diario Oficial, publicado el 6 de marzo del 2002.

Pérez-Calix, E. 1996. Flora y vegetación de la cuenca del lago de Zirahuén, Michoacán, México. Fascículo complementario XIII. Flora del Bajío y de regiones adyacentes. Instituto de Ecología, A. C. Centro Regional del Bajío. Pátzcuaro, Mich. 73 pp.

Ramos, L. J. y A. Novelo, R. 1993. Vegetación y flora acuáticas de la laguna de Yuriria, Guanajuato, México. Acta Bot. Mex. 25: 61-79.

Rojas, J. y A. Novelo, R. 1995. Flora y vegetación acuáticas del lago de Cuitzeo, Michoacán, México. Acta Bot. Mex. 31: 1-18. 
Rosas, M. C. 1997. La cuenca del lago de Zirahuén: Los avances del deterioro. Tesis de Maestría en Ciencias. Facultad de Biología, Universidad Michoacana de San Nicolás de Hidalgo. Morelia, Mich. 187 pp.

Titus, J. E. 1993. Submersed macrophyte vegetation and distribution within lakes: line transect sampling. Lake and Reservoir Management 7(2): 155-164.

\section{APÉNDICE}

Listado florístico de la vegetación acuática del lago de Zirahuén, Michoacán. (A) = acuática estricta, $(\mathrm{S})$ = subacuática, $(\mathrm{T})=$ tolerante, $\mathrm{HEE}=$ hidrófita enraizada emergente, $\mathrm{HES}=$ hidrófita enraizada sumergida, $\mathrm{HHF}=$ hidrófita de hojas flotantes, HLS= hidrófita libre sumergida. $*$ = Nuevos registros de flora acuática no citados previamente por Pérez-Calix (1996) y Chacón y Múzquiz (1991).

\section{CHLOROPHYTA}

Charophyceae

* Chara excelsa Allen (A), HES.

* Nitella opaca C. Agardh (A), HES.

* Nitella tenuissima (Desv.) Kütz. (A), HES.

EQUISETOPHYTA

Equisetaceae

Equisetum hyemale L. var. affine (Engelm.) A.A. Eaton (S), HEE.

\section{LYCOPODIOPHYTA}

Isoetaceae

Isoetes echinospora Durieu (S), HEE.

\section{MAGNOLIOPHYTA \\ Magnoliopsida}

Acanthaceae

Dyschoriste microphylla (Cav.) Kuntze (T), HEE.

Pseuderanthemum praecox (Benth.) Leonard (T), HEE.

Apiaceae (Umbelliferae)

Berula erecta (Huds.) Coville (A), HEE.

Hydrocotyle umbellata L. (S), HEE.

$H$. verticillata Thunb. (S), HEE. 
Asteraceae (Compositae)

Bidens bigelovii A. Gray (T), HEE.

B. pilosa L. (T), HEE.

Jaegeria glabra (S.Watson) B.L. Rob. (A), HEE.

J. pedunculata Hook. \& Arn. (T), HEE.

Solidago paniculata DC. (T), HEE.

Brassicaceae (Cruciferae)

Raphanus raphanistrum L. (T), HEE.

* Rorippa nasturtium-aquaticum (L.) Schinz \& Thell. (S), HEE.

Callitrichaceae

Callitriche deflexa A. Braun ex Hegelm. (S), HEE.

C. heterophylla Pursh (A), HEE.

Caryophyllaceae

Sagina procumbens L. (T), HEE.

Ceratophyllaceae

Ceratophyllum demersum L. (A), HES.

Fabaceae (Leguminosae)

Lotus repens (G.Don) Standl. \& Steyerm. (T), HEE.

Gentianaceae

Centaurium strictum (Schiede) Bruce (T), HEE.

Halenia crassiuscula B.L. Rob. \& Seaton (T), HEE.

Haloragaceae

* Myriophyllum aff. heterophyllum (Vell.) Verdc. (A.), HES.

Hydrophyllaceae

Phacelia platycarpa (Cav.) Spreng. (T), HEE.

Lentibulariaceae

Utricularia livida E. Mey. (S), HEE.

* Utricularia aff. macrorhiza Leconte (A), HLS.

Lythraceae

Lythrum vulneraria Schrank (T), HEE.

Menyanthaceae

Nymphoides fallax Ornduff (A), HHF. 
Nymphaeaceae

Nymphaea odorata Aiton subsp. odorata (A), HHF.

Onagraceae

Ludwigia peploides (Kunth) P. H. Raven (A), HEE.

* L. palustris (L.) Elliott (A), HES.

Polygonaceae

Polygonum aviculare L. (S), HEE.

$P$. hydropiperoides Michx. (S), HEE.

P. lapathifolium L. (S), HEE.

P. mexicanum Small (S), HEE.

$P$. punctatum Elliott (S), HEE.

Ranunculaceae

Ranunculus dichotomus Moc. \& Sessé (S), HEE.

$R$. donianus Pritz. (T), HEE.

$R$. geoides Kunth (T), HEE.

R. hydrocharioides var. natans (Nees) L.D. Benson (S), HEE.

$R$. petiolaris Kunth ex DC. (T), HEE.

Thalictrum pubigerum Benth. (T), HEE.

Rubiaceae

Galium sphagnophilum (Greenm.) Dempster (T), HEE.

G. trifidum L. (T), HEE.

Salicaceae

Salix bonplandiana Kunth (T), HEE.

Scrophulariaceae

Bacopa monnieri (L.) Wettst. (S), HEE.

Buchnera obliqua Benth. (T), HEE.

Calceolaria mexicana Benth. (T), HEE.

C. tripartita Ruiz \& Pav. (T), HEE.

Mimulus glabratus Kunth (S), HEE.

Pedicularis mexicana Zucc. ex Benth. (S), HEE.

Veronica peregrina L. (S), HEE.

$V$. polita Fr. (S), HEE.

$V$. serpyllifolia L. (S), HEE.

Solanaceae

Physalis sulphurea (Fernald) Waterf. (T), HEE. 
Liliopsida

Alismataceae

Sagittaria latifolia Willd. (A), HEE.

S. platyphylla (Engelm.) J.G. Sm. (A), HEE.

Cyperaceae

Carex boliviensis van Heurck \& Müll. Arg. (T), HEE.

Cyperus canus Presl (S), HEE.

C. niger Ruiz \& Pav. (S), HEE.

C. aff. manimae Kunth (S), HEE.

C. odoratus L. (T), HEE.

C. prolixus Kunth (S), HEE.

C. semiochraceus Boeck. (S), HEE.

C. sesquiflorus (Torr.) Mattf. \& Kük. (S), HEE.

C. spectabilis Link (S), HEE.

C. virens Michx. (S), HEE.

Eleocharis dombeyana Kunth (S), HEE.

E. montevidensis Kunth (S), HEE.

Rhynchospora kunthii Nees (S), HEE.

Schoenoplectus californicus (C.A.Mey.) Steud. (A), HEE.

Eriocaulaceae

Eriocaulon microcephalum Kunth (S), HEE.

Juncaceae

Juncus acuminatus Michx. (S), HEE.

J. ebracteatus Liebm. (S), HEE.

J. effusus L. (S), HEE.

J. microcephalus Kunth (S), HEE.

Najadaceae

Najas guadalupensis (Spreng.) Magnus var. guadalupensis (A), HES.

Orchidaceae

Spiranthes graminea Lindl. (S), HEE.

S. hyemalis A. Rich. \& Galeotti (S), HEE.

S. schaffneri Rchb.f. (S), HEE.

Poaceae (Gramineae)

Echinochloa holciformis Kunth (S), HEE.

Leersia hexandra Sw. (A), HEE.

Panicum elephantipes Nees \& Trin. (S), HEE. 
Acta Botanica Mexicana 68: 1-38 (2004)

* Phragmites australis (Cav.) Trin. \& Steud. (S), HEE.

Setaria parviflora (Poir.) Kerguélen (T), HEE.

Potamogetonaceae

Potamogeton amplifolius Tuck. (A.), HES.

Potamogeton illinoensis Morong (A.), HES.

Potamogeton pusillus L. var. pusillus (A.), HES.

Typhaceae

* Typha domingensis Presl (A), HEE.

Typha latifolia L. (A), HEE.

Zannichelliaceae

* Zannichellia palustris L. (A), HES.

Recibido en julio de 2002. Aceptado en febrero de 2004. 